\title{
International progress and evaluation on interactive coupling effects between urbanization and the eco-environment
}

\author{
FANG Chuanglin ${ }^{1,2}$, 'LIU Haimeng ${ }^{1,3}$, LI Guangdong ${ }^{1}$ \\ 1. Institute of Geographic Sciences and Natural Resources Research, CAS, Beijing 100101, China; \\ 2. Xinjiang University, Urumqi 830046, China; \\ 3. University of Chinese Academy of Sciences, Beijing 100049, China
}

\begin{abstract}
Global urbanization is exerting severe stress and having far-reaching impacts on the eco-environment, and yet there exists a complex non-linear coupling relationship between the two. Research on the interactive coupling effect between urbanization and the eco-environment will be a popular area of study and frontier in international earth system science and sustainability science in the next 10 years, while also being a high-priority research topic of particular interest to international organizations. This paper systematically collates and summarizes the international progress made in research on interactive coupling theory, coupling relationships, coupling mechanisms, coupling laws, coupling thresholds, coupling models and coupling optimization decision support systems. The research shows that urbanization and eco-environment interactive coupling theories include the Kuznets curve theory, telecoupling theory, planetary boundaries theory, footprint family theory and urban metabolism theory; most research on interactive coupling relationships is concerned with single- element coupling relationships, such as those between urbanization and water, land, atmosphere, climate change, ecosystems and biodiversity; the majority of research on interactive coupling mechanisms and laws focuses on five research paradigms, including coupled human and nature systems, complex social-ecological systems, urban ecosystems, social-economic-natural complex ecosystems, and urbanization development and eco-environment constraint ring; the majority of interactive coupling simulations use STIRPAT models, coupling degree models, multi-agent system models and big data urban computer models; and research has been carried out on urbanization and eco-environment coupling thresholds, coercing risk and optimal decision support systems. An objective evaluation of progress in international research on interactive coupling between urbanization and the eco-environment suggests that there are six main research focal points and six areas lacking research: a lot of research exists on macroscopic coupling effects, with little research on urban agglomeration and scale coupling effects; considerable research exists on sin-
\end{abstract}

Received: 2016-04-27 Accepted: 2016-05-06

Foundation: Major Program of the National Natural Science Foundation of China, No.41590840, No.41590842

Author: Fang Chuanglin (1966-), PhD and Professor, mainly engaged in urban development and planning studies.

E-mail: fangcl@igsnrr.ac.cn

*Corresponding author: Liu Haimeng (1989-), PhD Candidate, specialized in urban geography and regional planning. E-mail: haimengliu@163.com 
gle-dimension coupling effects, with little on multiple-dimension coupling effects; a great deal exists on "one-to-one" dual- element coupling effects, with little on "many-to-many" multiple-element coupling effects; a lot exists on positive feedback coupling effects, and little on negative feedback coupling effects; a great deal exists on empirical coupling effects, and little on theoretical coupling effects; a great deal exists on the use of simple quantitative methods, and little on using integrated simulation methods. Future studies should focus on coupling effects between urbanization in urban agglomerations and the eco-environment, spatial scale coupling effects, multi-dimensional coupling effects, telecoupling effects, "one-to-many" and "many-to-many" element coupling effects, and positive and negative feedback coupling effects. There is also a need to strengthen the development and application of dynamic models for multi-element, -scale, -scenario, -module and -agent integrated spatiotemporal coupling systems and further improve theoretical innovations in coupling effect research and integrate and form complete and diverse coupling theoretical systems.

Keywords: urbanization; eco-environment; interactive coupling effect; international progress; overall evaluation and prospects

\section{Interactive coupling effects between urbanization and the eco-environment as a new frontier in international research}

The historical development of global urbanization shows that it is accelerating, causing actual or potential harm to the eco-environment. By 2014, 54\% of the world was urbanized, and the United Nations predicts that $66 \%$ of the world's population will be living in urban areas by 2050. An extremely complex non-linear interactive coupling and coercing relationship exists between urbanization and the eco-environment, but the question of how to manage that relationship is a difficult and pressing one for academia and governments, and it is quickly becoming a strategic problem of global importance. Research on the interactive coupling relationship between urbanization and the eco-environment is set to become a popular area of study in international earth system science and sustainability science in the next 10 years (Kates et al., 2001; Clark, 2007; Reid et al., 2010).

\subsection{Basic content and types of interactive coupling effects between urbanization and the eco-environment}

The process of urbanization is one of the most important manifestations of the evolution of human social development, while the eco-environment is the natural setting and support system that humans rely on for survival and to thrive. Both urbanization and the eco-environment are classic examples of complex systems, and an extremely complex non-linear interactive coupling and coercing relationship exists between them (Qiao and Fang, 2005).

An interactive coupling relationship between urbanization and the eco-environment means a dynamic relationship of interdependence, inter-coordination and mutual promotion as well as coordinated development between elements of the urbanization system and elements (or subsystems) of, and movements in, the eco-environment system. This includes interactive coupling effects of various human elements within the urbanization system and interactive coupling effects of various natural elements within the eco-environment system, as well as non-linear interactive coupling effects involving one-to-one, one-to-many and many-to-many elements within the urbanization and eco-environment systems. An analysis 
of the types of coupling shows that interactive coupling effects between urbanization and the eco-environment include scale coupling effects, telecoupling effects, element coupling effects, function coupling effects, structure coupling effects and pattern coupling effects, with coupling periodicity, measurability and regularity observable between the different types of coupling effects. The coupling process also has open, non-linear, self-organizing, and fluctuating, multiple feedback and scale nesting characteristics.

\subsection{Interactive coupling effects between urbanization and the eco-environment as the forefront of international research}

As far back as 1991 the World Health Organization warned that the world faced a serious deterioration in the natural environment and a rapid reduction in the quality of life of people living in urban areas, and that urbanization would have a major impact on global climate change, which threatened the future survival of the human race. In 1995, the United Nations Assistant Secretary-General Wally N'Dow warned in An Urbanizing World: Global Report on Human Settlements 1996 "Urbanization holds out both the bright promise of an unequalled future and the grave threat of unparalleled disaster, and which it will be depended on what we do today," (Habitat, 1996).

In 2003, Nature published a study that discussed the impact of urbanization and land-use change on climate (Kalnay and Cai, 2003), which laid its focus on air pollution and carbon emissions in China resulting from urbanization (Zhang et al., 2012; Liu Z et al., 2015). In 2008, Science published a study which argued that urban areas are hot spots of eco-environmental problems (Grimm et al., 2008a) and reported on Chinese urbanization and the country's resource and environmental protection efforts (Normile, 2008). It also published articles such as "The Urban Transformation of the Developing World" and "The Size, Scale, and Shape of Cities"; started to view urbanization issues in developing countries, changes in land use and land cover as a result of urbanization, changes in urban, regional and global geochemical cycles, the relationship between urbanization and climate change, and changes in urban biodiversity as important research topics (Montgomery, 2008; Batty, 2008). In 2009, Science published a study by US scientist David Parrish and Professor Zhu Tong of Peking University entitled "Clean Air for Megacities", which pointed out the significant impact of air pollution in megacities, including Beijing and Shanghai, has on human health, and argued that the 19 megacities (as of 2007, and defined as cities with populations over 10 million) also provide an opportunity to mitigate climate change by controlling air pollution (Parrish and Zhu, 2009).

In April 2014, the Committee on New Research Opportunities in the Earth Sciences at the National Science Foundation identified in an article entitled "New Research Opportunities in the Earth Sciences" seven major research topics that will be prioritized in the earth sciences in the coming decade, including hydrogeomorphic-ecosystem responses to natural and anthropogenic change. The article also argued that changes to terrestrial ecosystems are due to human activities, such as agriculture and urbanization. "Future Earth 2025 Vision" published in 2014 looked at the links between global environmental change and human wellbeing and development, and listed urbanization and its risks as one of the eight key areas of future global research. 


\subsection{The interactive coupling effect between urbanization and the eco-environment is a high priority research theme of international organizations}

As resource and environmental issues have worsened with human socio-economic development and urbanization, the United Nations has issued a series of global action plans over the decades, including the "Declaration of the United Nations Conference on the Human Environment" in 1972, "Rio Declaration on Environment and Development" in 1992, "Agenda 21 " in 1992 and "Millennium Development Goals" in 2000. Since the 1970s, more and more international organizations have turned their attention to research on these topics and a series of major research programs and organizations have been set up to tackle specific issues, including the Man and Biosphere Program, Intergovernmental Panel on Climate Change, Beijer Institute of Ecological Economics, International Human Dimension Programme on Global Environmental Change, Resilience Alliance and Program in Dynamics of Coupled Natural and Human Systems (Table 1).

In 2005, the International Human Dimensions Programme on Global Environmental Change formulated a scientific research program entitled Urbanization and Global Environmental Change, a core project on global environmental change, which proposes to strengthen research on the coupling relationship between urbanization and global environmental change using cross-temporal and cross-spatial scale approaches, parallel and comparative studies across regions, and research that provides effective communication to the public and policy makers. The core project seeks to develop a better understanding of the interactions and feedback between global environmental change and urbanization at the local, regional and global scales, with an emphasis on coupling humanities and natural sciences and using an interdisciplinary perspective to solve issues related to the coupling relationship between human activities and the environmental system.

A Millennium Ecosystem Assessment report entitled "Ecosystems and Human Well-being" published in 2005 carried out a special assessment of urban systems and argued that rising urban populations and economic development were producing increased pressure on global ecosystems, thereby affecting ecosystem services. It particularly highlighted the vulnerability of urban ecosystems due to the effects of climate change.

The Future Earth initiative announced in 2012 brings together four major existing projects on global environmental change, namely the World Climate Research Programme, the International Geosphere-Biosphere Programme, DIVERSITAS and the International Human Dimensions Programme on Global Environmental Change. It aims to strengthen ties between the natural and social sciences to provide needed scientific knowledge, technical methods and solutions to help the world, regions and individual countries respond to global environmental change. It also seeks to promote sustainable global and regional development and takes as its core objective the observation, analysis and simulation of changes to natural and social systems, especially the dynamic characteristics of interactions between people and the environment. The program tries to understand the links between global environmental change and human wellbeing and development, with a focus on observing, explaining, understanding and projecting earth, environmental and societal system trends, drivers and processes and their interactions and anticipating global thresholds and risks. Of these, urbanization is the most intense human activity on Earth's surface, and its thresholds, risks 
Table 1 Major international research programs on the interactive coupling effect between urbanization and the eco-environment

\begin{tabular}{|c|c|c|c|}
\hline Project name & Research focus & $\begin{array}{l}\text { Main source of } \\
\text { funding }\end{array}$ & $\begin{array}{l}\text { Years } \\
\text { active }\end{array}$ \\
\hline $\begin{array}{l}\text { Man and the Biosphere } \\
\text { Programme }\end{array}$ & $\begin{array}{l}\text { Uses methods from ecology to study the rela- } \\
\text { tionship between people and the environment; } \\
\text { studies and tests the effects and action mecha- } \\
\text { nisms of the increasing influence human activi- } \\
\text { ties have on different ecosystems; predicts } \\
\text { changes to the biosphere and its resources as a } \\
\text { result of human activities and the effect on hu- } \\
\text { manity itself }\end{array}$ & UNESCO & $\begin{array}{c}1971- \\
\text { present }\end{array}$ \\
\hline $\begin{array}{l}\text { Intergovernmental } \\
\text { Panel on Climate } \\
\text { Change }\end{array}$ & $\begin{array}{l}\text { Assesses scientific, technical and } \\
\text { socio-economic information relevant to the un- } \\
\text { derstanding of the risk of global climate change } \\
\text { and its socio-economic effects and proposes } \\
\text { mitigation and adaption measures }\end{array}$ & $\begin{array}{l}\text { World Meteoro- } \\
\text { logical Organiza- } \\
\text { tion, United Na- } \\
\text { tions Environment } \\
\text { Programme }\end{array}$ & $\begin{array}{c}1988- \\
\text { present }\end{array}$ \\
\hline $\begin{array}{l}\text { Beijer Institute of Eco- } \\
\text { logical Economics }\end{array}$ & $\begin{array}{l}\text { Combines economics and ecology, with a focus } \\
\text { on urban ecological economic systems, ecosys- } \\
\text { tem management, behavior, economics and na- } \\
\text { ture networks, and complex system resilience }\end{array}$ & $\begin{array}{l}\text { Royal Swedish } \\
\text { Academy of Sci- } \\
\text { ences, Kjell and } \\
\text { Märta Beijer } \\
\text { Foundation }\end{array}$ & $\begin{array}{c}1991- \\
\text { present }\end{array}$ \\
\hline $\begin{array}{l}\text { International Human } \\
\text { Dimensions Pro- } \\
\text { gramme on Global } \\
\text { Environmental Change }\end{array}$ & $\begin{array}{l}\text { Seeks to describe, analyze and understand the } \\
\text { human dimensions of global environmental } \\
\text { change; researches land use/land cover change, } \\
\text { institutional factors of global environmental } \\
\text { change, human security, sustainable systems of } \\
\text { production and consumption, food and water } \\
\text { issues, and the global carbon cycle }\end{array}$ & $\begin{array}{l}\text { Belmont Forum of } \\
\text { funding agencies }\end{array}$ & $\begin{array}{c}1996- \\
2014\end{array}$ \\
\hline $\begin{array}{l}\text { Dynamics of Coupled } \\
\text { Natural and Human } \\
\text { Systems }\end{array}$ & $\begin{array}{l}\text { Complex coupling mechanisms of coupled } \\
\text { natural and human systems at diverse spatio- } \\
\text { temporal and organizational scales }\end{array}$ & $\begin{array}{l}\text { US National Sci- } \\
\text { ence Foundation }\end{array}$ & $\begin{array}{l}2000- \\
\text { present }\end{array}$ \\
\hline Resilience Alliance & $\begin{array}{l}\text { Complex adaptive system dynamics; complex- } \\
\text { ity, flexibility and resilience of social-ecological } \\
\text { systems }\end{array}$ & $\begin{array}{l}\text { IATP, ESA, WWF } \\
\text { and other funds }\end{array}$ & $\begin{array}{l}\text { 1999- } \\
\text { present }\end{array}$ \\
\hline $\begin{array}{l}\text { The Millennium } \\
\text { Ecosystem Assessment }\end{array}$ & $\begin{array}{l}\text { Assesses threats to the world's ecosystems, } \\
\text { plants and animals; promotes conservation and } \\
\text { sustainable use of ecosystems }\end{array}$ & $\begin{array}{l}\text { WTO, United Na- } \\
\text { tions Environment } \\
\text { Forum, World Bank }\end{array}$ & $\begin{array}{c}2001- \\
2005\end{array}$ \\
\hline $\begin{array}{l}\text { Land Use and Land } \\
\text { Cover Change }\end{array}$ & $\begin{array}{l}\text { Seeks to increase understanding of dynamics of } \\
\text { land use and land cover change to reveal the } \\
\text { basic process of interactions between the global } \\
\text { environmental system that humans rely on for } \\
\text { survival and developing systems of production }\end{array}$ & $\begin{array}{l}\text { Belmont Forum of } \\
\text { funding agencies }\end{array}$ & $\begin{array}{c}1992- \\
2014\end{array}$ \\
\hline $\begin{array}{l}\text { Intergovernmental } \\
\text { Platform on Biodiver- } \\
\text { sity and Ecosystem } \\
\text { Services }\end{array}$ & $\begin{array}{l}\text { Seeks to strengthen links between the scientific } \\
\text { community and policy makers in the areas of } \\
\text { biodiversity and ecosystem services to promote } \\
\text { the use of scientific knowledge in government } \\
\text { decision-making and better protect global bio- } \\
\text { diversity and enhance ecosystem services }\end{array}$ & $\begin{array}{l}\text { United Nations } \\
\text { Environment Pro- } \\
\text { gramme }\end{array}$ & $\begin{array}{c}2012- \\
\text { present }\end{array}$ \\
\hline Future Earth & $\begin{array}{l}\text { Research on three themes: Dynamic Planet, } \\
\text { Global Sustainable Development and Transfor- } \\
\text { mations towards Sustainability; observe, ex- } \\
\text { plain, understand and project earth, environ- } \\
\text { mental and societal system trends, drivers and } \\
\text { processes and their interactions and anticipate } \\
\text { global thresholds and risks; of these, urbaniza- } \\
\text { tion is the most intense human activity on } \\
\text { Earth's surface, and its thresholds, risks and } \\
\text { critical points are research frontiers }\end{array}$ & $\begin{array}{l}\text { International } \\
\text { Council for Sci- } \\
\text { ence, International } \\
\text { Social Science } \\
\text { Council, UNESCO }\end{array}$ & $\begin{array}{c}2014- \\
2023\end{array}$ \\
\hline
\end{tabular}


and critical points are research frontiers. In September 2013, the China Association for Science and Technology organized an international conference in Beijing called "Future Earth in China", which looked at issues that need to be addressed in China and that are related to sustainable capacity building, including the research topics of the effects of Asian urbanization on the regional environment and society, and interactions with health.

\section{International progress in the interactive coupling effect between ur- banization and the eco-environment}

Urbanization basically covers the processes of population urbanization (population migration and mobility), spatial urbanization (urban sprawl, landscape change, regional transformation, increased numbers of towns and cities, and urban expansion), economic urbanization (industrial restructuring) and social urbanization (lifestyle changes). The eco-environmental system basically means land use and land cover (soil environment and impervious surfaces), water resources (water balance), biodiversity, the atmosphere $\left(\mathrm{PM}_{2.5}\right.$ and $\mathrm{SO}_{2}$ ), energy consumption, $\mathrm{CO}_{2}$ emissions, the urban thermal environment, and ecosystem carbon and nitrogen cycles. Rapid urbanization has put enormous pressure on the eco-environment, which is mainly reflected in the increased resources extracted from the environment as a result of improvements in people's lifestyles and consumption structures (Seto et al., 2010). Since the 1990s, many scholars have carried out research on the coupling relationship between sub-systems or elements of urbanization and the eco-environment (Ren et al., 2003), while increasing numbers of others have analyzed the non-linear coupling relationship and coupling characteristics of the interactions between eco-environmental natural systems and urbanized human systems (Hull et al., 2015). International research on the interactive relationship between urbanization and the eco-environment is varied, but it mainly looks at the coercing and promotional effects of urbanization on the eco-environment, the constraining and carrying effect of the eco-environment on urbanization, as well as coupling evaluations, mechanisms, laws and simulations between the two, with new progress made in coordinating urbanization and the eco-environment through empirical research (Fang, 2015; Costantini and Monni, 2008; Kates et al., 2001). The research covers a number of disciplines, including ecology, geography, management, economics and environmental studies (Kennedy et al., 2011; Satterthwaite, 2008; Salim and Shafiei, 2014; Scholz and Binder, 2011). Case studies have been conducted on a variety of countries and regions, including Europe, the US, Russia and China (Barbera et al., 2010; Alnawaiseh et al., 2015; Zanella et al., 2014; Bao and Fang, 2007), with a tendency to look at watersheds, ecologically vulnerable areas, urbanized areas and metropolitan areas (Fang, 2015a; Zawar-Reza et al., 2010; Meerow and Newell, 2015). Studies have taken as their scope the world, countries, provinces, cities and parts of cities, with the main focus being cities (Luo et al., 2009; Yang et al., 2015; Anderson and O'farrell, 2012; Brown, 2012). The research relates to a variety of theories and models, including the footprint family, environmental Kuznets curve, telecoupling and urban metabolism theories, and methods including the STIRPAT model, coupling degree, multi-agent model and big data urban computing methods.

\subsection{Theory of interactive coupling between urbanization and the eco-environment}

As an area of research where a range of disciplines intersect, scholars from a range of scien- 
tific backgrounds have proposed and developed a series of theories on interactive coupling between urbanization and the eco-environment, including the environmental Kuznets curve hypothesis, urban metabolism theory, telecoupling theory, footprint family theory, planetary boundaries theory, social-economic-natural complex systems theory (Wang et al., 2011), urban vulnerability theory (Adger, 2006), eco-efficiency theory (Hellweg et al., 2005) and environmental justice theory (Wolch et al., 2014).

\subsubsection{Environmental Kuznets curve}

In 1994, Gene Grossman and Alan Kreuger used econometrics and panel data from 42 developed countries to show that as the economy of a city develops, a graph of the quality of the city's environment shows an inverted U-shaped curve, known as the environmental Kuznets curve (EKC) hypothesis. Since then, scholars have conducted empirical tests at the global, regional and national scale (Aslanidis and Iranzo, 2009; Akbostanci et al., 2009; Shahbaz et al., 2014) and continued, expanded and extended the hypothesis. For example, Gangadharan and Valenzuela (2001) analyzed the positive and negative causal relationships with income, health and environment, Heerink et al. (2001) analyzed the curvilinear relationship between income inequality and the environment, and Cole (2003) revised the EKC based on economic development, trade and the environment. Caviglia-Harris et al. (2009) used ecological footprint as an indicator of the eco-environment to test the global EKC and found that it did not have an inverted U-shaped curve, mainly due to energy consumption. A large volume of Chinese studies have shown that a weak inverted U-shaped curve exists for China's per capita income and the presence of $\mathrm{SO}_{2}$ and $\mathrm{CO}_{2}$ but, in empirical terms, the EKC is restricted by the research samples and methods (He, 2009; Jalil and Mahmud, 2009). Dongfeng et al. (2013), meanwhile, looked at the Kuznets curve in relation to China's urbanization and found that a win-win situation of urbanization and sustainable development can be achieved in China. Research on the EKC has received a lot of local and national attention, and as the environment worsens due to urbanization and interest grows in the environment, research on the EKC is set to increase.

\subsubsection{Telecoupling theory}

System coupling mechanisms are extremely complex and accompany vulnerability and adaptability (Walker et al., 2004). In 2005, ecologist Steward Pickett was the first to divide complex coupling mechanisms into organizational connectivity, spatially explicit structure and historical contingency, and establish a multidimensional concept model of biocomplexity (Pickett et al., 2005). He also proposed the content, a structure and a research framework for a five-dimensional human ecosystem in humane metropolis (Pickett et al., 2011). In 2013, Jianguo Liu proposed the concept of telecoupling (Liu et al., 2013), establishing and leading a research network on coupled human and natural systems (CHANS). Liu argued that migration, tourism, trade, species diffusion, technology transfers and investment are all important telecoupling processes. Using the trade in soybean and protection of the habitat of the giant panda as case studies, Liu built multi-scale coupling models, emphasizing that future CHANS telecoupling research should focus on comparative studies of multi-scale systems, consider action mechanisms between socio-economic and environmental systems, and integrate sending, receiving and overflow systems in the telecoupling system (Liu J G et al., 2015a). Harvard theorist Neil Brenner believes that urbanization should be seen as a global 
historical process and be extended to every corner of the globe, and the research paradigm should shift toward "planetary urbanization" analyzing, at the theoretical level, different scales of social space production, reproduction and transformation (Brenner, 2014; Brenner, 1999).

Moser and Hart (2015) constructed a framework for analyzing the effects of economic and societal teleconnections, such as trade, insurance, energy, food, immigration and the military, on climate change. Using land footprint and material flow accounting, Bruckner and others discussed methods of, and research progress in, measuring telecoupling in the global land system (Bruckner et al., 2015). Developing countries exporting raw materials and finished products to developed countries increase the vulnerability of humans to environmental stimuli, which leads to social unrest and deterioration of essential ecological system services by the local population, while manufacturers of export products produce considerable pollution, putting workers in developing countries at risk (Liu J G et al., 2015; Liu et al., 2007a). Urbanization and eco-environment telecoupling transcends space and natural and administrative boundaries. On the one hand, internal coupling and coupling between coupled human and nature systems transcends multiple nested spatial scales, from local to global (Pickett et al., 2011). Local coupling is affected by relatively large-scale processes, which are interposed by larger scale processes and ultimately produced against the backdrop of global processes (Liu and Diamond, 2005). Part of the global-scale coupling is produced by the interaction and impact of local processes, and global- or regional-scale coupling is produced as a result of remote human activities and large-scale natural processes. Globalization of human activities and the rapid movement of people, goods and services show that humans are experiencing a new era of regional and global co-evolution in their ecological and socio-economic systems. On the other hand, interactions between humans and nature through such things as trade and animal migration transcend political or ecosystem boundaries. Markets and governments can make decisions that affect people and ecosystems in faraway places (Lenschow et al., 2015).

\subsubsection{Planetary boundaries}

The planetary boundaries theory is a recently proposed sustainable development concept regarding global environmental thresholds for human activities. The concept was proposed in a paper entitled A Safe Operating Space for Humanity published in Nature by Rockström et al. First of all, it defines the biophysical thresholds for a number of global environmental problems and states that pressure from human activities has already affected the stability of the earth system, leading to frequent unexpected environmental changes across the globe, and that humanity has already transgressed three planetary boundaries, namely climate change, rate of biodiversity loss and changes to the global nitrogen cycle (Rockström et al., 2009). This theory attracted unprecedented attention and debate within academic circles, and both Science and Nature published follow-up reports (Erb et al., 2012; Lewis, 2012; Kareiva, 2012). The planetary boundaries theory uses a series of control variables to characterize environmental issues, such as $\mathrm{CO}_{2}$ concentration in the atmosphere, consumptive use of runoff resources, industrial and agricultural nitrogen fixation, phosphorous inflow to oceans, land surface under cropland, seawater saturation and $\mathrm{O}_{3}$ concentration to characterize climate change, water use, nitrogen and phosphorous emissions, land use, ocean acidification, 
stratospheric ozone depletion and loss of biodiversity, respectively (Galaz et al., 2012; Ragnarsdottir et al., 2011). In a study published in Science, Steffen et al. (2015) revised and updated the framework of planetary boundaries, emphasizing the supporting role of cross-scale coupling and regional heterogeneity, and defining two core boundaries - climate change and biosphere integrity - which once again drew widespread attention and discussion (Jaramillo and Destouni, 2015; Gerten et al., 2015). However, US environmental organization the Breakthrough Institute argues that the limits do not have any real significance to humans as we have always found solutions to obstacles throughout history and that concepts like environmental carrying capacity are not applicable to humans (Fang K et al., 2015). What's more, setting empirical values on social and ecosystem thresholds is extremely difficult. But based on the previous literature and case studies, Walker and Meyers (2004) established a threshold database and argued that flexible thinking and the complete understanding of uncertainty are effective ways to solve this problem (Walker and Salt, 2012).

\subsubsection{Footprint family}

The concept of an ecological footprint was first proposed by Canadian ecological economist William E. Rees in 1992, which he went on to develop together with his doctoral student Mathis Wackernagel (Rees and Wackernagel, 1996; Wackernagel and Rees, 1998). As human understanding of the complex, integral and global characteristics of environmental issues deepens, any single footprint index is unable to provide a comprehensive assessment of environmental impact. The concept of a footprint family, however, marks a gradual shift in focus from a single index to multiple indexes (Ridoutt and Pfister, 2014). In 2012, Galli provided the first detailed discussion on the independent concept of a footprint family, giving it the following specific definition: "a set of indicators able to track human pressure on the surrounding environment, where pressure is defined as appropriation of biological natural resources and $\mathrm{CO}_{2}$ uptake, emission of GHGs, and consumption and pollution of global freshwater resources. Three key ecosystem compartments are monitored, namely the biosphere, atmosphere, and hydrosphere through the Ecological, Carbon and Water Footprint, respectively," (Galli et al., 2012). A study in Science in 2014 explained that land, water, energy, materials and other footprints have an important role in fair and effective human trade and sustainable use of resources, serving as a reference for the scientific assessment of the environmental sustainability of human activities (Hoekstra and Wiedmann, 2014). Čuček comprehensively reviewed the definitions, methods and units of measurement of the various footprint indices, and proposed a series of socio-economic footprint indices for limiting the footprint family to environmental sustainability (Čuček et al., 2012). Fang systematically compared the concepts and methodological similarities of the ecological footprint, carbon footprint, water footprint and energy footprint, and analyzed potential advantages and drawbacks of the four footprints (Fang et al., 2014).

\subsubsection{Urban metabolism}

Urban metabolism is the huge system of production, transformation, consumption and exchange of materials, resources, energy and services between a city and its external environment. This system consumes large quantities of energy resources and environmental materials at the same time as it manufactures, absorbs and converts the magnitude of value required to satisfy a city's requirements for socio-economic development (Poruschi, 2015; 
Moore, 2007). In 1965, Abel Wolman proposed the concept of urban metabolism in his book The Metabolism of Cities, stating that operations of an urban system are a metabolic process (Wolman, 1965). In the 1990s, the concept of an urban metabolic process was widely used to measure urban or regional socio-economic metabolism (Barles, 2010). The concept of urban metabolic processes at that time was not restricted to the direct release of fumes and waste from urban physical structures and habitats, it also included human health and wellbeing (Townsend, 2000). The underlying cause of many recent issues, such as resource and energy shortages, eco-environmental destruction, fall in quality of life and poor quality of economic growth, in the course of urban and regional development in China is an imbalance in urban metabolic processes (Zhang et al., 2011). In the 21st century, research on urban metabolism has been more systematic, with scholars using classic models, such as system dynamics and ecological network analysis, and energy analysis, to study metabolic efficiency and environmental benefits of different cities (Xia et al., 2015; Shahrokni et al., 2015; Gustafson et al., 2014). Lili Qu et al. looked at the urban agglomeration of Suzhou, Wuxi and Changzhou using the life-cycle theory to discuss the internal material metabolic mechanisms of the agglomeration and found that the cities should focus on integrating solid waste recycling to save energy and reduce emissions, while improving production technology to reduce the negative impacts of waste. They also applied the theory to evaluate urban agglomeration resource management and waste streams (Qu et al., 2013). Kennedy et al. (2014) proposed a multi-layered set of indicators to measure the metabolic state of megacities, which included a definition of a large urban agglomeration and material flow analysis. They also considered the role of utilities in the provision of services and regulatory actions that, along with public governance, can influence urban metabolism. The first layer of the indicator set is the basic information of the megacity, while the second layer is its biophysical characteristics, the third layer is the urban metabolism characteristics and the fourth layer is the role of utilities. In their study, Zhang et al. (2015a) summarized half a century of development of urban metabolism theory, stating that future analysis should focus on establishing a multi-layered, unified and standardized category system to support the creation of a consistent database and help governments to achieve sustainable development. Newell and Cousins (2015), meanwhile, systematically reviewed the epistemological and model-making approaches of the "three ecologies" of urban metabolism: industrial ecology, Marxist ecologies and urban ecology.

\subsection{Interactive coupling between urbanization and eco-environmental subsystems}

Eco-environmental subsystems closely related to the process of urbanization include water systems, land systems, atmospheric systems, energy systems, climate systems and ecosystems.

\subsubsection{Interactive coupling between urbanization and water resources}

From analyses of the interactive coupling relationship between urbanization and water resources, international scholars have found that water resources play both a facilitating and restricting role on urbanization (Seto et al., 2010; Fang et al., 2007). When a city is growing excessively quickly, for example, and there is a lack of corresponding infrastructure, urban development will tend to adopt unsustainable methods of exploiting land and water re- 
sources, leading to water shortages and weakened environmental carrying capacity, thereby impeding urbanization (Orubu and Omotor, 2011). Changes in urban lifestyles will have a profound impact on the future water footprint of cities (Hubacek et al., 2009), and the pattern of water use, sources of wastewater and quality of wastewater of urban agglomerations are closely connected (Popa et al., 2012). Whether cities are vulnerable to water constraints depends on factors such as formal water infrastructure, the rate of land-use change and spatial patterns, the adaptability of residents and land-based water systems. At the same time, this vulnerability is dynamic, variable across space and scale-dependent (Srinivasan et al., 2013). Many other scholars have analyzed the spatiotemporal feedback relationship between urbanization and water ecology, water balance and water pollution (Venkatesan et al., 2011; Shao et al., 2006; Haase, 2009).

\subsubsection{Interactive coupling between urbanization and land resources and land use}

Analyses of the interactive coupling relationship between urbanization and land resources and land use show that changes in stages of industrialization and urbanization result in land use changes (Swyngedouw, 2009; Kalnay and Cai, 2003), and are particularly closely related to changes in construction land (Kline et al., 2001), the expansion of which is one of the most important manifestations of urbanization. Studies have shown that a long-term equilibrium exists between China's urban construction land, economic growth and urbanization, and increased area of urban construction land in China is mainly due to accelerated urbanization (Choy et al., 2013), while changes in land use in urban areas can be summarized as due to population, level of economic development, industrial restructuring in agriculture, regional industrial restructuring and foreign investment (Zhang S M et al., 2010). The rapid development of real estate land and construction of urban infrastructure that accompanies rapid increases in population and increased living standards have been found to be the main driving forces of changes in the urban landscape (Wei and Ye, 2014). Growth of construction land and changes in land change distribution and speed, as well as land use restructuring has a significant impact on carbon emissions and the ecological landscape (Trusilova and Churkina, 2008; Deng et al., 2009). On the other hand, land resources are the most important basic development factor for urbanization, and their supporting role in population changes and production development has been of interest to various scholars (Kurucu and Chiristina, 2008).

\subsubsection{Interactive coupling between urbanization and the atmosphere}

Analyses of the interactive coupling relationship between urbanization and the atmospheric environmental system show that air pollution not only seriously affects the global climate, but also harms the human body and impacts the health of urban residents, reduces quality of life in cities, and significantly hinders urban development (Aunan and Wang, 2014; Young et al., 2012). In their study "Clean Air for Megacities" published in Science, Parrish and Zhu (2009) pointed out the significant impact air pollution was having on people's health in megacities, including Beijing and Shanghai, and argued that the 19 megacities (as of 2007, and defined as cities with populations over 10 million) also provide an opportunity to mitigate climate change by controlling air pollution. As Chinese cities urbanize and develop industrially, air pollution has become one of China's most serious environmental problems (Chan and Yao, 2008). There is now sufficient evidence to prove that exposure to outdoor air 
pollution in China itself constitutes a serious health hazard (Kan et al., 2009), and that it led to the premature deaths of 1.6 million people in 2014 (Matus et al., 2012; Rohde and Muller, 2015). It has been estimated that the cost of air pollution driven by health impacts and loss of labor productivity ran at $6.5 \%$ of China's gross domestic product each year between 2000 and 2010 (Crane and Mao, 2015). As centers of human activity, urbanized areas produce large volumes of air pollution and emissions, leading to higher concentrations of $\mathrm{PM}_{2.5}(\mathrm{He}$ et al., 2012), which gradually affects the environment in surrounding areas (Zhao et al., 2012).

The urban air quality index (AQI) has become the indicator of livability of most concern to urban residents (Han et al., 2015b). Related studies have shown that the main reasons for air pollution in China are the large population, industrial pollutants and high emissions, combustion of biomass and regional transport (Li et al., 2013; Zhang et al., 2015b), with significant regional differences and spatial dependency (Fang C L et al., 2015). Popa et al. (2012) looked at multiple physical and chemical properties of wastewater and the concentration of pollutants, as well as their distribution, in the Danube and discussed the relationship between water use, wastewater sources and wastewater quality of an urban agglomeration in Romania. Jinyuan Xin et al. (2012), meanwhile, looked at Beijing's $\mathrm{PM}_{2.5}$ data for the period of the 2008 Olympics, the results of which showed that restrictions on production and driving in the urban agglomeration caused concentrations of $\mathrm{PM}_{2.5}$ to fall during that period in the Beijing, Tianjin and Hebei area (controlling emissions contributed $62 \%-82 \%$, meteorological conditions contributed $18 \%-38 \%$ ), thereby fulfilling the objective of staging a "green Olympics".

\subsubsection{Interactive coupling between urbanization and climate}

Analyses of the interactive coupling relationship between urbanization and climate show that climate change is the biggest challenge ever to the continuation of human civilization. The fifth assessment report of the Intergovernmental Panel on Climate Change (IPCC) stated that over half of global warming that has taken place since the 1950s was caused by human activities, and using Coupled Model Intercomparison Project Phase 5 (CMIP 5), it predicted that global warming would continue in the future and that by the end of the 21 st century the average surface temperature of Earth would rise by $0.3-4.8^{\circ} \mathrm{C}$ compared to the period 1986 to 2005 (Pachauri et al., 2014). In 1990, Jones et al. (1990) published a study entitled "Assessment of Urbanization Effects in Time Series of Surface Air Temperature over Land" in Nature which concluded that the global air temperature rise of $0.5^{\circ} \mathrm{C}$ in the past 100 years could be related to urbanization. In 2003, Kalnay and Cai published a study entitled "Impact of Urbanization and Land-Use Change on Climate", also in Nature, which argued that the contribution of urbanization and land-use change to global climate change over the past century was $0.35^{\circ} \mathrm{C}$. Liu et al. (2011) also found a close correlation between temperature rises in cities and the speed of urbanization. In addition, rapid urbanization has been found to pose an enormous threat to forests, grasslands, wetlands and other natural ecosystems (Falcucci et al., 2007; Ficetola et al., 2010; Magura et al., 2004; Oliver et al., 2014; Ortega-Álvarez et al., 2009; Pekin et al., 2012; Pereira et al., 2010; Wei et al., 2014). A report in The Lancet in 2015 pointed out that climate change seriously threatens global health and warned that, without a rapid response, the achievements of human development from the latter half of the last century will have been in vain, suggesting that the best opportunity for 
saving global health in the 21 st century is a rapid response to climate change (Wang and Horton, 2015). Climate change has also been found to lead to a global increase in the probability of extreme weather, with an intensified urban heat island effect (Argüeso et al., 2014; Corburn, 2009). Future sea level rises caused by climate change will inevitably affect urbanization in coastal regions, with large areas of land being submerged and prone to severe flooding, which will affect production and energy resources, causing further environmental problems (Castan Broto and Bulkeley, 2013; Gu et al., 2011). In response to this, Mark Pelling argues, governments should implement measures, including administrative and technical measures and urban planning rules, which respond to climate change (Pelling, 2010).

However, one study has suggested that climate change may promote urbanization in Africa due to the reorganization of water resources and industrial production (Henderson et al., 2015). On the other hand, another study has shown that land cover significantly affects the surface temperature of densely populated areas, with the main factors being artificial thermal discharge, building shape, vegetation type and climate change (Burski et al., 2014). Feng Jinming et al. used atmospheric models and an urban canopy model to simulate the effect of urban sprawl in the Yangtze River Delta, the Beijing-Tianjin-Hebei urban agglomeration and the Pearl River Delta on regional climates. The results showed that urban sprawl in the three urban agglomerations had increased the surface air temperature of the urban areas by $1^{\circ} \mathrm{C}$, with more noticeable temperature changes in summer and at night. At the same time, thermal stress increased by 0.5 units, regional solar radiation increased and water vapor decreased, all of which mainly affected regional precipitation, especially in summer (Feng et al., 2014). Escudero et al. (2014), on the other hand, looked at the effects of Mediterranean urban agglomerations on ozone concentration and found a significant correlation between changes in ozone concentration and atmosphere and $\mathrm{NO}_{\mathrm{x}}$ emissions, with changes in $\mathrm{NO}_{\mathrm{x}}$ emissions strongly influencing changes in ozone.

2.2.5 Interactive coupling between urbanization and energy consumption and carbon emissions

Analyses of the interactive coupling relationship between urbanization and energy consumption and carbon emissions show a close correlation between urbanization and energy consumption and carbon emissions, with energy sources affecting and restricting the level and pace of urbanization and determining urbanization development and trends, while population, industrialization and land urbanization are all heavily dependent on energy sources (Ming, 2015). Against a backdrop of a shortage in global energy resources and fierce competition for carbon emission rights, China is continuing to urbanize rapidly, and it is estimated that another 400 million people will have moved to urban areas from the countryside by 2050, while China's per capita carbon dioxide emissions will continue to increase until 2020 (Wang et al., 2014a), meaning contradictions between urbanization and energy resources are set to become more prominent (Lin and Ouyang, 2014). Studies have shown that urbanization in low-income countries reduces energy consumption, whereas urbanization in high-income countries increases energy consumption, but urbanization has been shown to increase carbon emissions regardless of the type of country it occurs in (Poumanyvong and Kaneko, 2010). Indeed, Liddle and Lung (2010) proved the existence of a positive correlation between urbanization and $\mathrm{CO}_{2}$ emissions, and Martinez-Zarzoso and Maruotti (2011) discovered that a graph of urbanization and $\mathrm{CO}_{2}$ emissions has an inverted U-shaped curve. 
Using a dynamic land ecosystem model, however, Zhu et al. (2012) looked at 20 emerging countries and discovered a non-linear relationship between urbanization and $\mathrm{CO}_{2}$ emissions, and not an inverted U-shaped curve. They also measured and evaluated carbon dynamic mechanisms in urbanized areas of the southern US from 1945 to 2007 and found that in the past 63 years urbanization has caused $209 \mathrm{Tg}$ of carbon emissions and that the carbon sequestration rate of urban ecosystems constantly fell following a change in the nature of land use. Al-mulali et al. (2012) used the fully modified ordinary least square (FMOLS) to look at the long-term relationship between urbanization, energy consumption and $\mathrm{CO}_{2}$ emissions for the period 1980-2008 in seven regions, namely, East Asia and the Pacific, East Europe and Central Asia, Latin America and the Caribbean, Middle East and North Africa, South Asia, Sub-Saharan Africa, and Western Europe, the results of which showed that $84 \%$ of the countries have a positive long-term relationship between urbanization, energy consumption and $\mathrm{CO}_{2}$ emissions, while only $16 \%$ of the countries have mixed results.

\subsubsection{Interactive coupling between urbanization and ecosystems and biodiversity}

Analyses of the interactive coupling relationship between urbanization and ecosystems and biodiversity show that, since the industrial revolution, the rapid development of urbanization and industrialization have seriously threatened biodiversity and ecosystems, such as forests, grasslands and wetlands (Hamer and McDonnell, 2008; Hayashi et al., 2009; Wei et al., 2014), and changes in land use and land cover in urban areas, in particular, have directly affected natural ecosystems and biodiversity (Gill et al., 2008; Kohsaka, 2010). New research has shown that some of the problems from the process of urbanization have increased the vulnerability of ecosystems and threatened the health of nature and human well-being (Bennett et al., 2015; Walker et al., 2002), forcing us to focus on the value of ecosystem services and their positive impact on sustainable urbanization in future urbanization development and planning (Cumming et al., 2014; Zhang Y et al., 2010). For developing countries, the rapid urbanization accompanying economic globalization has forced many cities to wantonly exploit and develop already vulnerable natural resources and ecosystems through land reclamation, resource extraction, overgrazing, disorderly land use and urban expansion, in order to obtain comparative advantages and economic benefits, which is affecting and changing the natural environment we depend on for survival, dwindling natural resources and threatening biodiversity (Aronson et al., 2014; Adamo, 2010). On the other hand, the majority of protected areas in low- and middle-income countries can affect the growth of new cities as the distance between cities and protected areas decreases (McDonald et al., 2008). In an article entitled "Scenarios for Global Biodiversity in the 21st Century" published in Science, Pereira et al. (2010) used an observation and comparison model to analyze species extinction, changes in species abundance, habitat loss and changes in distribution to predict the evolutionary scenarios for global terrestrial, freshwater and marine biodiversity, which showed that biodiversity would continue to decline in the 21 st century. Haas and Ban, meanwhile, used the concepts of landscape metrics and ecosystem services to investigate land cover changes and the magnitude and speed of urbanization and evaluate possible impacts on the environment in China's largest and most important urban agglomerations, namely, Beijing-Tianjin-Hebei, Yangtze River Delta and Pearl River Delta. The results showed that rapid urbanization has led to a loss of natural ecosystems, landscape fragmentation and significantly reduced the value of ecosystem services, while urban growth was the 
fastest in the Beijing-Tianjin-Hebei agglomeration, followed by the Yangtze River Delta and Pearl River Delta, resulting in a continuously fragmented landscape and substantial decreases in ecosystem service values of approximately RMB 18.5 billion yuan (coastal wetlands and farmland being the largest contributors). These results indicate that urbanization adversely affects natural and rural landscapes (Haas and Ban, 2014).

\subsection{Mechanisms and laws of interactive coupling between urbanization and the eco- environment}

Studying the mechanisms and laws of interactive coupling between the two large systems of urbanization and the eco-environment is a difficult but extremely worthwhile undertaking. Because urbanization in Western developed countries is already in a mature and stable phase, studies on the coupling relationship between human activities and the natural environment by Western scholars have tended to focus on urban settlements and involved in-depth discussions on mechanisms and analyses of case studies; whereas, in developing countries like China, which are currently in a phase of rapid urbanization, problem-oriented studies on the coupling relationship between urbanization and the eco-environment are just becoming more popular. This includes the following five major areas of research: coupled human and natural systems, social-ecological systems, urban ecology, social-economic-natural complex ecosystems, and the urbanization development ring and eco-environment constraint ring systems (Table 2).

Table 2 International research on mechanisms and laws of interactive coupling between urbanization and the eco-environment

\begin{tabular}{|c|c|c|c|}
\hline Coupling system name & Coupling mechanism name & Coupling law name & $\begin{array}{l}\text { Coupling } \\
\text { force }\end{array}$ \\
\hline $\begin{array}{l}\text { Coupled human and } \\
\text { natural systems }\end{array}$ & $\begin{array}{l}\text { Non-linear telecoupling } \\
\text { cross-border coupling } \\
\text { mechanism interactive } \\
\text { coercing mechanism }\end{array}$ & $\begin{array}{l}\text { Hereditary, emergence, transformability, } \\
\text { scale continuity, time lag, resilience, } \\
\text { heterogeneity, telecoupling }\end{array}$ & Adaptation \\
\hline $\begin{array}{l}\text { Social-ecological } \\
\text { systems }\end{array}$ & $\begin{array}{l}\text { Interactive nesting mecha- } \\
\text { nism }\end{array}$ & $\begin{array}{l}\text { Coupling adaptability, timing, } \\
\text { self-adaptability, cross amalgamation, } \\
\text { threshold uncertainty, gradual change }\end{array}$ & Resilience \\
\hline Urban ecology & $\begin{array}{l}\text { Positive and negative } \\
\text { feedback mechanisms } \\
\text { metabolism mechanism }\end{array}$ & $\begin{array}{l}\text { Ecological responsiveness, positive and } \\
\text { negative feedback, periodicity, metabolic }\end{array}$ & Evolution \\
\hline $\begin{array}{l}\text { Social-economic-natural } \\
\text { complex ecosystems }\end{array}$ & $\begin{array}{l}\text { Multi-system collaborative } \\
\text { mechanism complex niche } \\
\text { mechanism }\end{array}$ & $\begin{array}{l}\text { Feedback, restrictive, urban S-shaped } \\
\text { growth }\end{array}$ & Synergy \\
\hline $\begin{array}{l}\text { Urbanization develop- } \\
\text { ment ring and } \\
\text { eco-environment } \\
\text { constraint ring systems }\end{array}$ & $\begin{array}{l}\text { Dynamic control mecha- } \\
\text { nism phased coupling } \\
\text { mechanism }\end{array}$ & $\begin{array}{l}\text { Coupling fissionability, dynamic hierar- } \\
\text { chy, random fluctuation, non-linear } \\
\text { collaboration, threshold, warning }\end{array}$ & Control \\
\hline
\end{tabular}

2.3.1 Non-linear mechanisms and hereditary, resilience, emergence and transformability laws of coupled natural and humans systems

The research paradigm of coupled natural and human systems is represented by the Dynamics of Coupled Natural and Human Systems project, which is supported by the US National Science Foundation and brings together researchers in the fields of ecology, geography, economics and sociology. In a study published in Science, Dietz et al. (2003) discussed the 
impact of tropical rain forests and climate change on global human activities and systems management, and described the characteristics of human and natural cross-border coupling. Manson (2008) adopted an epistemological approach and suggested that research on complex human-environmental systems should focus on scale continuum and scale effects. A paper by Liu et al. (2007b) entitled "Complexity of Coupled Human and Natural Systems", also published in Science, concluded that couplings between human and natural systems vary across space, time, and organizational units in six case studies from five continents (Kenya, China, Washington and Wisconsin in the US, Mexico and Sweden), and that this coupling exhibited non-linear dynamics with thresholds, reciprocal feedback loops, time lags, resilience, heterogeneity and mutations. They also concluded that past couplings have legacy effects on present conditions and future possibilities and discussed the evolution of interactions in coupled human and natural systems from direct to indirect, and from adjacent links to distant links, from the local scale to the global scale, and from simple models and processes to more complex ones (Liu et al., 2007c). Another study involving Liu published in Science in 2015, discussed further the emergent properties and complexity of this coupling system, and pointed out that a number of influential integrated frameworks, such as ecosystem services, environmental footprints, human-nature nexus, planetary boundaries, and telecoupling and tools for systems integration have been developed and tested. They also suggested that future research should focus on incorporating more human and natural components simultaneously, integrating spatiotemporal scales, identifying and quantifying spillover systems, accounting for feedbacks and translating findings into policy and practice (Liu J G et al., 2015a). Newell et al. (2005) blended the concepts of dynamics and system, organization and scale, controlling models, management and policy, and adaptation and learning to construct a "conceptual template". An and Lopez-Carr (2012) analyzed the limiting effect of natural system inputs and outputs on human systems and discussed human decision making and resilience in the face of coupled human and natural systems. Werner and McNamara (2007) proposed the concept framework of strongly-coupled human-landscape systems and argued that these complex systems can use heterogeneous agent models to predict the non-linear behavior of different subjects.

2.3.2 Interactive nesting mechanisms of social-ecological systems and coupling adaptability, cross-amalgamation and gradual change laws

Social-ecological systems research groups, including the Resilience Alliance, International Institute of Applied Systems Analysis and Stockholm Resilience Centre, are constantly developing and expanding the concept of resilience and providing innovative research paradigms to answer questions related to social-ecological systems. In 2001, for example, in "Panarchy: Understanding Transformations in Human and Natural Systems", Crawford S. Holling made good use of the concepts of resilience, timing and adaptability to propose a famous cross-scale system of adaptive nested cycles, which moved the coupling system forward a step epistemologically (Gunderson, 2001; Holling, 2001). Walker et al. (2004) used the "basin of attraction" to discuss the flexibility, adaptability and transformability of social-ecological systems. Trosper (2005) feels that social-ecological systems require multi-disciplinary analysis and emphasized the role of cultural systems in social-ecological systems. Folke et al., meanwhile, discussed the flexible methods for studying so- 
cial-ecological systems, emphasizing research on interactive coupling across temporal and spatial scales with regard to non-linear dynamics, thresholds, uncertainty and surprise, and how periods of gradual change interplay with periods of rapid change, as well as looking at adaptive governance of social-ecological systems from a social dimension (Folke et al., 2005; Folke, 2006). Ramaswami et al. (2012) adopted an industrial ecology perspective of integrating urban metabolism with life cycle assessment and articulated a cross-scale and multi-disciplinary approach to social, ecological and infrastructure integration in order to shape cities toward sustainability. In 2015, a core magazine in this field, Ecology and Society, published a special feature consisting of a series of articles under the title "A Framework for Analyzing, Comparing and Diagnosing Social-Ecological Systems", which proposed specific frameworks and indicators for studying social-ecological systems in the areas of the environment, resource systems, pollution, individuals, social organizations and government regulation (Bots et al., 2015; McGinnis and Ostrom, 2014; Binder et al., 2013).

2.3.3 Urbanization and ecosystem positive and negative feedback mechanisms and ecological response

Urban ecologists are concerned with the strength of ecosystems in urban areas and important ecological services for the human population and human well-being. Grimm et al., for example, built a pioneering conceptual framework on urban ecosystems and discussed its application to the US cities of Baltimore and Phoenix (Grimm et al., 2000) as well as ecological responses to urbanization (Grimm et al., 2008b). They also published a paper in Science entitled "Global Change and the Ecology of Cities", which analyzed the relationship between changes in the ecology of urban landscapes and global changes, arguing that global urbanization is the main factor affecting climate change at multiple scales and that the demand for materials due to production and human consumption has led to land use and land cover changes, a loss of biodiversity, local and regional pollution of water systems and increased urban waste and emissions, thereby affecting the global biogeochemical cycles and local climates (Grimm et al., 2000; Grimm et al., 2008a). Alberti et al. integrated human factors and urban ecology to construct a framework for studying the effect of different urban development models on ecosystems, carrying out empirical research on the effects on aquatic ecosystems (Alberti et al., 2003; Alberti et al., 2007). Alberti also described feedback mechanisms from human activities to ecosystem evolution in the course of global urbanization. He then proposed a framework linking urban patterns to ecosystem functions and discussed a set of hypotheses based on the empirical evidence established in the literature (Alberti, 2010). Shlomo Angel used a sample of 120 cities for the period 1990-2000 and 3,646 cities for the year 2000 to discuss urban density, speed of urban sprawl, fragmentation of built-up areas and urban ecological footprint and their interactions (Angel et al., 2005; Angel, 2012). In addition, many scholars have looked at the impact models and mechanisms of landscape change in the course of urbanization (Summers et al., 2015), carbon and nitrogen cycles (Lorenz and Lal, 2015; Gu et al., 2012), net primary productivity (Imhoff et al., 2004) and urban biodiversity (Hansen et al., 2005; Savard et al., 2000).

2.3.4 Social-economic-natural complex ecosystem collaborative mechanisms and urban S-shaped growth

As China's eco-environmental problems have become more acute as a result of urbanization, 
Chinese scholars have in recent years explored the topic of coupling between urbanization and the eco-environment from various angles. Ma and Wang (1984), for example, proposed the concept of a social-economic-natural complex ecosystem and used positive and negative feedback and the law of limiting factors from the principle of ecological compatibility to reveal the existence of feedback and restrictive mechanisms between the evolution of urbanization and the eco-environment, from which they concluded that urban growth exhibits a corresponding S-shaped curve (Wang et al., 2011). Qi et al. (2012), meanwhile, described the significant impacts of regional climate change, economic development, land use and constant increases in food production on arid regions in East Asia. Baolong Han et al. analyzed the complex niches of large Chinese cities in the course of population concentration from the perspective of environmental niches, the social and eco-environment, and economic niches (Han et al., 2014), and carried out a quantitative evaluation of ecological security in the Beijing-Tianjin-Hebei region (Han et al., 2015a). Based on remote sensing data of land use and the normalized difference vegetation index, Cui et al. (2015) constructed an environmental quality index to analyze the effect of Chinese urbanization over the previous ten years. Fang et al. (2016) constructed a system for evaluating resources, ecology, economies and societies to carry out an assessment of the urban vulnerability of Chinese cities.

2.3.5 Dynamic and control mechanisms and phased coupling laws of interactions between urbanization and the eco-environment

Fang and Huang used algebra and geometry to create logical compounds of the environmental Kuznets curve and an urbanization logarithmic curve, from which they deduced mathematical functions and geometric curves relating to the interactive coupling between urbanization and the eco-environment, expressed as power functions and a double exponential curve composed of exponential functions. Using scientific theory, they established a dynamic coupling degree model of coordinated development between urbanization and the eco-environment, which further revealed the presence of initial pre-exponential decay and latter index-improved phased coupling laws accompanying urbanization of regional eco-environments. The process of interactive coupling was divided into low-level coordination, antagonism, breaking-in and high-level coordination (Fang and Wang, 2013; Huang and Fang, 2003), and urbanization development models and paths analyzed in relation to arid northwest China (Fang et al., 2007; Fang and Lin, 2009). On the basis of this, interactive coupling laws for urbanization and the eco-environment, including coupling fission law, dynamic hierarchical law, random fluctuation law, non-linear collaborative law, threshold law and warning law were summarized (Fang and Yang, 2006). Liu et al. used collaborative learning and grey relational analysis to construct correlation degree and coupling degree models, which revealed the major factors in the coupling between urbanization and the eco-environment in Chinese provinces, and analyzed the spatiotemporal layout of the coupling degree between urbanization and the eco-environment in China (Liu et al., 2005; Liu et al., 2011).

\subsection{Quantitative modeling of interactive coupling between urbanization and the eco- environment}

Due to the complexity of interactive coupling between urbanization and the eco-environ- 
ment, coupling models and methods must be interdisciplinary in order to address issues (Singh et al., 2012). There have been many attempts at this by contemporary scholars using conceptual models and theoretical frameworks. Schlueter et al. (2012), for example, reviewed coupled social-ecological systems modeling from the perspective of natural resource management. Stevenson (2011) looked at the non-linear feedback relationship between five elements of the coupled human and natural system, namely, human well-being, environmental policy, human activities, stressors and ecosystem services, at multiple spatiotemporal scales. Filatova et al. systematically summarized the theories and conceptual models of coupled social-ecological systems, reviewed changes to, and the evolution of, models and emphasized regime shifts in statistical modeling, system dynamics, and equilibrium and agent-based modeling (Filatova et al., 2015; Polhill et al., 2016). Liu et al. (2011) used an inclusive sustainable development model, interpretive structural model and grey relational technology to evaluate the coupling relationship between urbanization and the eco-environment, and used systems dynamics and artificial neural networks to simulate future environmental changes. Wang et al. (2014b), meanwhile, used a double exponential curve model and took the Beijing-Tianjin-Hebei urban agglomeration as an example to verify the interactive coupling relationship between urbanization and eco-environmental systems. They discovered that the coupling relationship of 10 of the cities in the urban agglomeration exhibited changes to the double exponential curve. In addition to the above research, other scholars have found U-shaped and N-shaped non-linear relationships between urbanization and the eco-environment (Friedl and Getzner, 2003). However, carrying out genuine quantitative analysis of the interactive coupling between urbanization and the eco-environment remains a major challenge to contemporary scholars. Here, a few quantitative studies on this issue that use a number of newer models and methods are introduced.

\subsubsection{STIRPAT model}

Ehrlich and Holdren (1971) first proposed the establishment of the IPAT equation to reflect the impact of human activities on the natural environment. Afterward, on the foundation of the traditional IPAT model, Waggoner and Ausubel (2002) proposed the ImPACT analysis model, stating that, in addition to population, affluence and technology, factors affecting the natural environment should include consumption per unit of production and efficiency. However, IPAT and ImPACT do not accurately represent the non-proportional effects and non-monotonic effects of driving forces on the environment. In order to overcome this drawback, York et al. refined the IPAT equation by developing the concept of ecological elasticity, namely, the ecological elasticities of population, affluence and technology, and analyzed driving forces of environmental impacts. Unlike the IPAT and ImPACT equations, the STIRPAT (Stochastic Impacts by Regression on Population, Affluence, and Technology) model is not an accounting equation; rather, it is a stochastic model, therefore it is also called a statistical model for assessing environmental impacts (York et al., 2003b; York et al., 2003a). The model equation is as follows:

$$
I=a P^{b} A^{c} T^{d} e
$$

where $I$ is impact, $P$ is population, $A$ is affluence, $T$ is technology and $a, b, c$ and $d$ are exponents of $P, A$ and $T$, respectively, and $e$ is the error term. Application of the STIRPAT model and elasticity coefficients solves the question of how to verify the impact of changes 
to driving forces on environmental changes in empirical analysis. As such, in recent years, STIRPAT has been well applied to studies on the impact of various human activities on the environment. The most frequent application has been to study human driving forces of carbon emissions (Wang et al., 2013; Roberts, 2011), and a study by Noorpoor and Kudahi (2015) has shown that population size, per capita GDP, electricity intensity and consumption of energy resources for electricity consumption positively influence $\mathrm{CO}_{2}$ emissions, while electricity generation by hydropower, renewable energies and nuclear energy do so negatively. Yuan et al. (2015) used a dynamic threshold STIRPAT model, which suggested that wealth is the most important deciding factor in long-term carbon emissions, followed by urban population. They also found that the influence of affluence variability on $\mathrm{CO}_{2}$ emissions was mainly determined by the degree of trade openness in high-income areas, and by higher industrial levels in low-income areas. In addition, using this model, Liddle (2013) examined the relationship between private transport energy consumption and several variables, including population, income and urban density. Dai et al. (2015), meanwhile, used a STIRPAT model to carry out empirical research on rural non-point source pollution in the course of urbanization in China by looking at population, economies of scale, energy consumption and finance.

\subsubsection{Coupling models}

Coupling degree is used to describe the interaction between elements of or within a system and their degree of influence on each other. A coordinate is a benign interaction between two or more elements of, or within, a system and is a concentrated expression of sustainable development of the benign interaction. Coupling coordinative degree is the degree of harmony between two elements of, or within, a system in the course of development and reflects the system trend for disorder to order (Qiao and Fang, 2005). Usually, the physics concept of capacity coupling and the capacity coupling coefficient model are used as the basic model for analyzing an interactive coupling relationship between the integrated elements of urbanization and the eco-environment and analyzing the trend of coupling coordination. The model equation is as follows:

$$
C_{n}=\left\{\left(u_{1} \times u_{2} \times \ldots \times u_{m}\right) /\left[\prod\left(u_{i}+u_{j}\right)\right]\right\}^{1 / n}, \quad(m=1,2 ; i, j=1,2, i \neq j)
$$

where $C_{n}$ is the coupling degree model, and $u$ represents the contribution of the degree of order of the subsystem to the whole system. The coupling coordinative degree model is as follows (Liu et al., 2011):

$$
D=(C \times T)^{1 / 2}, T=a \times U_{1}+b \times U_{2}
$$

where $D$ is the coupling coordinative degree, $C$ is the coupling degree, $T$ is the subsystem integrated coordinated index, $U_{i}(i=1,2)$ represents the two system of urbanization and the eco-environment, and $a$ and $b$ are determined parameters. Because of its simplicity, the coupling degree model has physical significance and has been used a great deal in studies on the interactive coupling between urbanization and the eco-environment. Bao and Fang (2009) evaluated the restrictive intensity of water resources on urbanization in arid regions of China. Li et al. and Wang et al. analyzed the coupling relationship between urbanization and the eco-environment in Chinese coastal cities and for the urban agglomeration of Beijing-Tianjin-Hebei, respectively (Li et al., 2012; Wang et al., 2014b). Tang (2015) integrated 
indexes to study coupling between the tourism industry and the environment. Liu et al. (2014) integrated the matter-element model and coupling coordinative degree model to analyze evolution of the social-economic-ecological system in the process of urbanization.

\subsubsection{Multi-agent model}

A multi-agent system (MAS) is a loose network made up of multiple agents, with each agent engaging in exchanges, cooperation and even competition based on its character and rules of behavior. An MAS can be used to study the macroscopic laws of a system by simulating and observing the microscopic behavior of the subjects, which helps provide a more rational and accurate explanation of the evolutionary mechanisms of complex systems (Balaji and Srinivasan, 2010; Borne et al., 2003). Therefore, there is considerable scope for using MASs in urban development simulations. This type of bottom-up modeling strategy combines complex adaptive systems theory, artificial life and distributed artificial intelligence technology, and has already developed into another important method for analyzing and simulating complex systems (Jjumba and Dragicevic, 2012; Torrens and Benenson, 2005). In a study entitled "New Ways of Looking at Cities" published in Science in 1995, Batty stated that top-down macroscopic city models have gradually been supplanted by models that simulate the macroscopic behavior of cities based on microscopic interactions between subjects (Batty 1995). In another study, Batty (2005) discussed the concept of agents at different spatial scales based on spatial evolution as reaction and diffusion. Heckbert et al. (2010) described the applications of agent-based modelling in ecological economics and discussed advancing the empirical calibration and validation of models through mixed methods, including surveys, interviews, participatory modeling, and, notably, experimental economics to test specific decision-making hypotheses. Agents represent real or abstract entities in geographic space, and multiple agents co-exist in a common environment. They interact with each other and their environments, and each agent is able to act autonomously, with their behavior the result of self-perception, learning, reasoning, decision-making and interactions (Tian et al., 2011). In a 2005 study, An et al. used the Wolong Giant Panda Nature Reserve as a case study and tracked the life history of local individuals and the dynamics of households to establish a multi-agent, multi-scale integrated model of a complex coupled system. In a separate study, An et al. developed a CHANS-oriented protocol based on the overview, design concepts, and details (ODD) framework to help CHANS modelers and other researchers build, document and compare CHANS-oriented ABMs, the lessons from which include how to represent agents and the landscape, the need for standardized modules for CHANS ABMs, the impacts of scheduling on model outcomes, and precautions in interpreting "surprises" in CHANS model outcomes (An et al., 2014).

\subsubsection{Big data and urban computing models}

With the maturity of sensing technologies and computing environments, a range of urban big data has become available, including data on traffic flows, meteorology, road networks, points of interest, mobile tracking and social media usage. If used properly, this big data can not only immediately reflect problems in cities, but can also be used to address challenges that cities face (Ferreira et al., 2013). The questions of how to interpret this mountain of data to reveal social phenomenon and the laws of social development and how to find correlations and trends hidden in big data to discover the coupling mechanisms between human 
activities and nature in urban agglomerations are all of great interest to contemporary scholars, governments and companies. In "The Fourth Paradigm: Data-intensive Scientific Discovery" Microsoft Research pointed out that scientific research is in a new, fourth paradigm of discovery based on data-intensive science, involving data exploration, unified theory, experimentation and simulation (Hey et al., 2009). The identified research targets fall into the following four categories: real-time observation data, experimental data from scientific instruments, simulation data from test models and online data. Online data has been affected by the IT revolution and produced big behavioral data and big transaction data. Big behavioral data is mainly produced through social networks, such as Twitter, Sina Weibo and WeChat, as well as virtual communities; whereas, big transaction data is mainly based on the socialization of e-commerce.

Pijanowski et al. (2014) used big data to configure the GIS and neural network-based Land Transformation Model to run in a High Performance Computing (HPC) environment, allowing them to simulate urban growth. In a later study, Pfeffer et al. (2015) discussed the potential and challenges of using big data to address pressing urban issues and examined the potential of big data as a methodological tool with a case study involving data from Twitter. Jain et al. (2014) attempted to use visualizations of big data from cities to study urban air pollution. Shearmur (2015) took census data as an example to show the limitations and problems of using big data in urban geography.

Increased accessibility to big data and changes in data mining have given rise to urban computing (Shklovski and Chang, 2006; Kindberg et al., 2007). Urban computing refers to the use of big data from cities to address the pressing challenges of the cities themselves, as well as integrating, analyzing and mining a variety of heterogeneous data to extract knowledge and intelligence, and using that intelligence to create mutually beneficial outcomes for humans, the environment and cities (Zheng et al., 2014). Urban computing is an emerging and extremely important area of intersection, where computer science meets traditional city planning, transportation, energy, economics, environmental studies and sociology in urban space. The arrival of the era of big data has improved the feasibility of modeling micro-individuals, such as land, residents, households and businesses, and accelerated the possibility of accurately simulating cities, thereby providing a new powerful way to study the coupling relationship between humans and the environment at the micro-scale (Kukka et al., 2015; Zheng, 2015).

\subsection{The thresholds and coercing risk of the interactive coupling relationship between urbanization and the eco-environment}

In a study entitled "A Safe Operating Space for Humanity" published in Nature in 2009, Johan Rockström et al. argued that pressure from human activities has already affected the stability of the Earth system and led to frequent unexpected environmental incidents. The paper proposes the safe operating space for nine thresholds, of which, seven are climate change thresholds, including carbon dioxide, ozone, nitrogen and phosphorous, freshwater use, change in land use and biodiversity loss. It also includes chemical pollution and two indicators of atmospheric pollution. To date, they argue, humanity has already overstepped three of the nine thresholds, namely, climate change, biodiversity loss and interference with the nitrogen cycle (Rockström et al., 2009). A study by Mansencal et al. (2013) suggested 
that environmental changes in urban agglomerations can trigger greater incidence of diseases, and showed that the incidence of Tako-Tsubo cardiomyopathy is high in women over 60 in urban agglomerations in Europe, the US and Japan. Chowdhuri et al. (2011) assessed the earthquake risk in and around the Agartala urban agglomeration using digital microearthquake recorders for site response studies.

\subsection{Optimal decision support systems for interactive coupling between urbanization and the eco-environment}

In 2010, Pereira et al. published their study "Scenarios for Global Biodiversity in the 21st Century" in Science, which simulated scenarios for global biodiversity in the 21 st century. The article compared models and analyzed species extinction, changes in species abundance and changes in the loss and distribution of habitats to predict evolution scenarios for global terrestrial, freshwater and marine biodiversity. Their results suggested that biodiversity will continue to decline in the 21 st century (Pereira et al., 2010). In terms of multi-factor decision support systems for resources and the environment, the most commonly used decision-making methods include linear programming, Bayesian decision theory (Yu, 2013), model-driven decision support methods (Wierzbicki et al., 2000; Power and Sharda, 2007), and multiple object decision making support/multiple criteria decision making (Gwo-Hshiung, 2010). Multiple-objective solving strategies used in recent studies include goal-programming based on expert knowledge, the distance-based method, the weighting method and intelligent optimization algorithms (Yeh and Chuang, 2011). Intelligent optimization algorithms are the most widely used method and strategy in multiple objective optimization, including simulated annealing, genetic algorithms and ant colony optimization algorithms. Simulated annealing algorithms include multiple objective simulated annealing algorithms (Ulungu et al., 1999) and the Pareto simulated annealing algorithm. Genetic algorithms are one of the most optimal Pareto for solving multiple objective questions (Tan et al., 2015). Murata et al. (1996) and Altiparmak et al. (2006) proposed a multiple objective genetic algorithm for solving mathematical programming model issues, and used a weighted sum method to obtain Pareto-optimal solution for decision makers. Based on heuristic multiple objective decision making systems, Gen and Cheng (2000) and Yeh and Chuang (2011) proposed using a modified micro-genetic algorithm to solve Pareto optimality. Ant colony optimization was originally used to solve problems in single objective decision making, but was gradually applied to multiple objective problems (Donner et al., 2006; Tan et al., 2015).

In terms of intelligent decision support systems, Van Delden and Hurkens (2011) developed a common integrated spatial decision support system for urban and spatial planning that takes into account social, cultural, environmental and economic developments in an integrated fashion in order to achieve interactions between models from different disciplines, including economics, demographics, regional interaction, land use and transport. In order to identify a decision-making process for land use allocation, Cerreta and De Toro (2012) proposed a methodological approach for a Dynamic Spatial Decision Support System (DSDSS), named Integrated Spatial Assessment (ISA), to guide sustainable land use and management. Multi-agent technology is an effective new method of solving multidisciplinary, distributed and collaborative land-use planning decisions (Kurihara et al., 2005). Combining the MALPDSS system designed by the multi-agent method can support distributed collaborative 
group activities relatively well, improve the efficiency of user planning decisions and effectively enhance land use structure optimization and support decision capabilities (Feitosa et al., 2011). Fang (2011) constructed an urban industrial layout decision support system, which provided full technical support and information services to achieve the standardized management of urban industrial upgrading and optimization in China and to allow city, county and township governments to coordinate and regulate industry selection, investment, distribution and management.

\section{Overall assessment on interactive coupling effects between urbanization and the eco-environment}

Progress in international research on the urbanization-eco-environment interactive coupling relationship, mechanisms, theories, laws, methods, simulations and decision support systems has shown the following: global urbanization is seriously threatening and having a deep impact on the eco-environment, and an extremely complex non-linear coupling relationship exists between urbanization and the eco-environment. With regard to this complex non-linear relationship, scientists around the world have adopted both qualitative and quantitative research methods using different perspectives, dimensions and spatial scales in an attempt to show the coercing and interactive coupling effects between urbanization and the eco-environment and achieve positive progress. But owing to the complexity of this area of study, and due to ongoing uncertainty, change and intrazonality, despite the best efforts of scientists from various disciplines, numerous scientific questions continue to represent weak links, including how natural and human elements interact, influence each other and feedback to each other at different spatial scales and inside and outside different regional systems, and how significant their influence is and whether or not they can be regulated. Specific details of this are looked at below.

\subsection{Interactive coupling effect between urbanization in urban agglomerations and the eco-environment and on multiple spatial-scale coupling effects}

An analysis of research scales reveals that current studies have covered multiple scales, including the world, countries, provinces, cities and areas of cities, with the majority of studies on interactive coupling effects between urbanization and the eco-environment looking at the global and national macro-scales or the city scale, and fewer studies looking at urban agglomerations as well as coupling and nesting between different scales. At the local, regional and global scales, intensive urban material consumption and human activities have affected land use and land cover, biodiversity and hydrological systems, while cumulative effects have affected the global climate and brought changes to the environment. As a result, domestic and international scholars have tended to focus their research on cities and the environment. As global urbanization has accelerated, traditional urban geography has been unable to elucidate the interdisciplinary and even international characteristics of urban agglomerations. A look at case study areas reveals that the literature favors national-scale horizontal comparisons and coupling relationships of single cities, with a noticeable dearth of studies looking at the interactive coupling relationship between urbanization and the eco-environment in the core urban areas of urban agglomerations. Most recent studies on 
urban agglomerations have concentrated on the spatial expansion, economic development, and spatial structure and formation of urban agglomerations (Fang, 2015), with few looking in-depth at coupling mechanisms between urbanization in urban agglomerations and the eco-environment as well as resource and environment dynamic support system controls. On the other hand, urbanization is currently becoming planetary urbanization (Brenner, 2014), changes in elements of local urbanization are affecting people's health, and scale effects exist in the coupling mechanisms and laws between urbanization at the global, regional, national and local scales and the eco-environment. Therefore, an important trend of future research will be the interactive coupling relationship between urbanization and the eco-environment at the scale of urban agglomerations and from the perspective of scale coupling effects.

\subsection{Multiple-dimension coupling effects and telecoupling effects}

An analysis of the literature shows that, in terms of studies on the interactive coupling relationship between urbanization and the eco-environment, scholars from various disciplines have been constrained by disciplinary thinking and research paradigms, tending to focus on single dimensions of research, while ignoring the importance of other dimensions (Singh et al., 2012). For example, economists tend to focus on predictions in the dimension of time, geographers tend to focus on differences in the dimension of space, and management and sociology scholars tend to focus on interactive coupling between social organizations and groups. As far as studies on interactive coupling between urbanization and the eco-environment are concerned, foreign research groups mainly consist of geographers and ecologists, so they lack understanding of, and attention to, the temporal and organizational dimensions. Moreover, human activities are becoming increasingly globalized, and accelerating flows and networks of people, goods, technology, services, information and finance show that the human race is in a new era characterized by the common progress of natural and socio-economic systems at local and global scales, and the pattern and process of the evolution of these systems is multi-level by nature, with connections between levels, and multiple coupling and feedback between processes and scales. As such, future research on coupling between urbanization and the eco-environment should focus more on the processes and mechanisms of telecoupling and hidden coupling, pay attention to the organic integration of the spatiotemporal dimensions, attach importance to interdisciplinary research, and give overall consideration to the role and mechanisms of the temporal, spatial, organizational and representational dimensions.

\subsection{Research on "one-to-many" and "many-to-many" element coupling effects}

An analysis of element coupling effect studies shows that the majority of researchers have focused on "one-to-one" dual-element coupling effects, such as the coupling relationship between urbanization and single elements like water, land, resources, ecology, climate, environment or carbon emissions, revealing the coupling mechanisms and laws between single elements. There is still a lack of studies on "one-to-many" multiple-element coupling relationships and mechanisms and "many-to-many" coupling relationships and mechanisms. There is, therefore, a need in future for comprehensive studies of the coupling relationship, mechanisms and laws of urbanization and the eco-environment under the influence of multi- 
ple elements, studies on "many-to-many" multi-directional analyses of interactive coercive coupling and telecoupling mechanisms between the systems of urbanization and the eco-environment, and studies on coupling equations and curves that quantitatively express interactive coercion between the systems of urbanization and the eco-environment, in order to provide a quantitative scientific basis for achieving harmonious relationships between humans and water systems, land, resources, climate and carbon.

\subsection{Positive and negative feedback and interactive coupling effects between urbaniza- tion and the eco-environment}

An analysis of positive and negative feedback mechanisms and a survey of current theories and empirical research in the literature show that much of the research concerns the coercing effect of urbanization on the eco-environment, while there is little research on the constraining effect of the eco-environment on urbanization. Focal points and trends of future research include two-way interactive coupling effects between urbanization and the eco-environment and positive and negative feedback mechanisms. Current domestic and international studies mainly focus on the coercing effect of urbanization on the environment, such as the major impacts of accelerated urbanization and industrialization on land use and land cover (the soil environment and impervious surfaces), water resources (water balance), biodiversity, the atmosphere, energy consumption, carbon dioxide emissions, the urban thermal environment, ecosystem carbon and nitrogen cycles, ecosystem services and marine fisheries development. In contrast to this, at the other end of the feedback chain, there is relatively little research on the constraining effect of the eco-environment on urbanization, with few scholars taking an eco-environmental constraint perspective and integrating changes in the eco-environment and urbanization or comprehensively discussing the positive and negative feedback effects of the two major systems of humans and nature (Bao and Chen, 2015).

With the acceleration of urbanization in developing countries, achieving coordinated development between urbanization and the environment has become a central issue in world socio-economic development, and it is becoming a hot research topic internationally. The "2030 Agenda for Sustainable Development" adopted by the United Nations in 2015 listed the relationship between human development and the resource environment as an important issue. Many top international research institutions have also made the sustainable development of coupled human and natural systems core research topics, including the Sustainability Science Program of Harvard University's Kennedy School and the Coupled Human and Natural Systems Research Network of the US National Science Foundation. This shows that the focal point and trend of future research will be the two-way interactive coupling effects between urbanization and the eco-environment.

\subsection{Theoretical innovation in coupling effect research and form a complete and di- verse system of coupling theory}

An analysis of case studies and academic theories shows that current research covers multiple disciplines, including ecology, geography, management, economics and environmental studies, with case studies tending to cover watersheds, ecologically fragile areas, urbanized areas and metropolitan areas. The majority of research on coupling between urbanization, 
economic development and resources is based on local empirical case studies, and although this helps to provide a direct scientific basis and decision making reference for local sustainable development, in the long run it does not help people to deepen their understanding of the mechanisms and rules of the coupling relationship between humans and the land.

Einstein once said, "The aim of science is, on the one hand, as complete a comprehension as possible of the connection between perceptible experiences in their totality, and, on the other hand, the achievement of this aim by employing a minimum of primary concepts and relations." From this perspective, although there are a lot of relevant contemporary theories, especially the theoretical contributions of ecologists and environmental scientists, including the ecological footprint, urban metabolism, energy value, ecological economic efficiency, planetary boundaries and society-ecology system theories, but there is still no agreement on the overall theoretical framework for research on coupled human and natural (urbanization and the eco-environment) systems, with scholars still in the stage of viewing things from the perspective of their own discipline (Stevenson, 2011; Leslie et al., 2015; Steen-Adams et al., 2015). As a result, there is a need for a simple and intuitive description of the problem that can also integrate existing theoretical developments and give a complete explanation in simple terms of diverse coupling theoretical systems.

\subsection{Development and application of multiple-element, -scale, -scenario, -module, and -agent spatiotemporal coupling system dynamic models}

The content of current research is relatively macroscopic, and there are a lot of papers featuring qualitative discussions and that consider a variety of frameworks. For a long time, quantitative methods encountered a bottleneck when it came to the coupling relationship between the two complex systems of urbanization and the eco-environment. After integrating indexes of the two major systems, the majority of studies on coupling degree use mathematical formulas to carry out analysis but do not establish an interactive coupling system model between multiple factors, leaving them unable to show a causal relationship between, and the weighting of, multiple factors. Regression-based models can currently only simulate limited master control variables, but need to take urbanization and the eco-environmental system as a whole explanatory variable. However, current studies only take into account the coupling of systems within a specific area and between factors, while ignoring cross-regional and cross-scale open dissipative structural characteristics of urbanization and the ecosystem. It is very difficult to deal with this type of telecoupling relationship using traditional research methods. The urbanization and eco-environment coupling system has the classic characteristics of a complex system, namely, it is non-linear, self-organized, fluctuating and hierarchical, and involves feedback. Moreover, the emergence of complexity science has greatly contributed to the further development of science, progressing human understanding of objective things from linear to non-linear, from simple equilibrium to non-equilibrium dissipative structures, from simple reductionism to complex holism (Norberg and Cumming, 2013; Suh, 2005). Complex systems theory and complex network theory are gaining more and more attention in studies on urbanization and ecosystems. In addition, with the rapid development of computer science and the Internet, and the widespread application of big data mining techniques, urban computing and research on city and regional sustainable development based on big data has begun to flourish. Therefore, 
complexity science, simulations based on big data, top-down modeling multi-agent integrated research and other methods are becoming breakthrough points in current research on complex system coupling processes and mechanisms. Integrating big data and decision support systems to develop overall solutions to sustainable urban development is an important future application of studies. It is, therefore, necessary to strengthen research on, and experimental simulations of, urbanization and eco-environmental interactive coercing multi-element, -scale, -scenario, -module and -agent integrated spatiotemporal coupling system dynamic models supported by big data and cloud computing.

\section{References}

Adamo S B, 2010. Environmental migration and cities in the context of global environmental change. Current Opinion in Environmental Sustainability, 2(3): 161-165.

Adger W N, 2006. Vulnerability. Global environmental change, 16(3): 268-281.

Akbostanci E, Turut-Asik S, Tunc G I, 2009. The relationship between income and environment in Turkey: Is there an environmental Kuznets curve? Energy Policy, 37(3): 861-867.

Alberti M, 2010. Maintaining ecological integrity and sustaining ecosystem function in urban areas. Current Opinion in Environmental Sustainability, 2(3): 178-184.

Alberti M, Booth D, Hill K et al., 2007. The impact of urban patterns on aquatic ecosystems: An empirical analysis in Puget lowland sub-basins. Landscape and Urban Planning, 80(4): 345-361.

Alberti M, Marzluff J M, Shulenberger E et al., 2003. Integrating humans into ecology: Opportunities and challenges for studying urban ecosystems. BioScience, 53(12): 1169-1179.

Alnawaiseh N A, Hashim J H, Md Isa Z, 2015. Relationship between vehicle count and particulate air pollution in Amman, Jordan. Asia Pac J Public Health, 27(2): NP1742-51.

Altiparmak F, Gen M, Lin L et al., 2006. A genetic algorithm approach for multi-objective optimization of supply chain networks. Computers \& Industrial Engineering, 51(1): 196-215.

An L, Linderman M, Qi J et al., 2005. Exploring complexity in a human-environment system: An agent-based spatial model for multidisciplinary and multiscale integration. Annals of the Association of American Geographers, 95(1): 54-79.

An L, Lopez-Carr D, 2012. Understanding human decisions in coupled natural and human systems. Ecological Modelling, 229: 1-4.

An L, Zvoleff A, Liu J G et al., 2014. Agent-based modeling in coupled human and natural systems (CHANS): Lessons from a comparative analysis. Annals of the Association of American Geographers, 104(4): 723-745.

Anderson P M L, O'Farrell P J, 2012. An ecological view of the history of the city of Cape Town. Ecology and Society, 17(3): 12.

Angel S, 2012. Planet of Cities. Lincoln Institute of Land Policy. Cambridge, MA.

Angel S, Sheppard S, Civco D L et al., 2005. The dynamics of global urban expansion. World Bank, Transport and Urban Development Department Washington, DC.

Argüeso D, Evans J P, Fita L et al., 2014. Temperature response to future urbanization and climate change. Climate Dynamics, 42(7/8): 2183-2199.

Aronson M F, La Sorte F A, Nilon C H et al., 2014. A global analysis of the impacts of urbanization on bird and plant diversity reveals key anthropogenic drivers. Proc Biol Sci, 281(1780): 20133330.

Aslanidis N, Iranzo S, 2009. Environment and development: Is there a Kuznets curve for $\mathrm{CO}_{2}$ emissions? Applied Economics, 41(6): 803-810.

Balaji P G, Srinivasan D, 2010. Multi-agent system in urban traffic signal control. IEEE Computational Intelligence Magazine, 5(4): 43-51.

Bao C, Chen X J, 2015. The driving effects of urbanization on economic growth and water use change in China: A provincial-level analysis in 1997-2011. Journal of Geographical Sciences, 25(5): 530-544.

Bao C, Fang C L, 2007. Water resources constraint force on urbanization in water deficient regions: A case study of the Hexi Corridor, arid area of NW China. Ecological Economics, 62(3/4): 508-517.

Bao C, Fang C L, 2009. Integrated assessment model of water resources constraint intensity on urbanization in arid area. Journal of Geographical Sciences, 19(3): 273-286.

Barbera E, Currò C, Valenti G, 2010. A hyperbolic model for the effects of urbanization on air pollution. Applied Mathematical Modelling, 34(8): 2192-2202.

Barles S, 2010. Society, energy and materials: The contribution of urban metabolism studies to sustainable urban 
development issues. Journal of Environmental Planning and Management, 53(4): 439-455.

Batty M, 1995. New ways of looking at cities. Nature, 377: 574.

Batty M, 2005. Agents, cells, and cities: new representational models for simulating multiscale urban dynamics. Environment and Planning A, 37(8): 1373-1394.

Batty M, 2008. The size, scale, and shape of cities. Science, 319(5864): 769-771.

Bennett E M, Cramer W, Begossi A et al., 2015. Linking biodiversity, ecosystem services, and human well-being: Three challenges for designing research for sustainability. Current Opinion in Environmental Sustainability, 14: 76-85.

Binder C R, Hinkel J, Bots P W et al., 2013. Comparison of frameworks for analyzing social-ecological systems. Ecology and Society, 18(4): 26.

Borne P, Fayech B, Hammadi S et al., 2003. Decision support system for urban transportation networks. IEEE Transactions on Systems Man and Cybernetics Part C-Applications and Reviews, 33(1): 67-77.

Bots P W, Schlüter M, Sendzimir J, 2015. A framework for analyzing, comparing, and diagnosing social-ecological systems. Ecology and Society, 20(4): 18.

Brenner N, 1999. Globalisation as reterritorialisation: The re-scaling of urban governance in the European Union. Urban Studies, 36(3): 431-451.

Brenner N, 2014. Implosions/explosions: Towards a study of planetary urbanization. Jovis-Verlag.

Brown A, 2012. Scenario analysis: Urbanization emissions. Nature Climate Change, 2(6): 394-394.

Bruckner M, Fischer G, Tramberend S et al., 2015. Measuring telecouplings in the global land system: A review and comparative evaluation of land footprint accounting methods. Ecological Economics, 114: 11-21.

Burski Z, Wasilewski J, Mijalska-Szewczak I et al., 2014. Analysis of energy consumption of food transit in an urban agglomeration in Poland. Transportation Research Part D: Transport and Environment, 31: 165-175.

Castan Broto V, Bulkeley H, 2013. A survey of urban climate change experiments in 100 cities. Global Environmental Change, 23(1): 92-102.

Caviglia-Harris J L, Chambers D, Kahn J R, 2009. Taking the "U" out of Kuznets: A comprehensive analysis of the EKC and environmental degradation. Ecological Economics, 68(4): 1149-1159.

Cerreta M, De Toro P, 2012. Urbanization susceptibility maps: A dynamic spatial decision support system for sustainable land use. Earth System Dynamics Discussion, 3: 1159-1190.

Chan C K, Yao X, 2008. Air pollution in mega cities in China. Atmospheric Environment, 42(1): 1-42.

Chowdhuri S N, Singh O P, Majumdar R K, 2011. Site response studies in Agartala urban agglomeration. Natural Hazards, 59(1): 329-345.

Choy L H T, Lai Y, Lok W, 2013. Economic performance of industrial development on collective land in the urbanization process in China: Empirical evidence from Shenzhen. Habitat International, 40: $184-193$.

Clark W C, 2007. Sustainability science: A room of its own. Proceedings of the National Academy of Sciences, 104(6): 1737.

Cole M A, 2003. Development, trade, and the environment: How robust is the Environmental Kuznets Curve? Environment and Development Economics, 8: 557-580.

Corburn J, 2009. Cities, climate change and urban heat island mitigation: Localising global environmental science. Urban Studies, 46(2): 413-427.

Costantini V, Monni S, 2008. Environment, human development and economic growth. Ecological Economics, 64(4): 867-880.

Crane K, Mao Z, 2015. Costs of selected policies to address air pollution in China. RAND Corporation.

Čuček L, Klemeš J J, Kravanja Z, 2012. A review of footprint analysis tools for monitoring impacts on sustainability. Journal of Cleaner Production, 34: 9-20.

Cui E, Ren L, Sun H, 2015. Evaluation of variations and affecting factors of eco-environmental quality during urbanization. Environ Sci Pollut Res Int, 22(5): 3958-3968.

Cumming G S, Buerkert A, Hoffmann E M et al., 2014. Implications of agricultural transitions and urbanization for ecosystem services. Nature, 515(7525): 50-57.

Dai H J, Sun T, Zhang K et al., 2015. Research on rural nonpoint source pollution in the process of urban-rural integration in the economically-developed area in China based on the improved STIRPAT model. Sustainability, 7(1): 782-793.

Deng J S, Wang K, Hong Y et al., 2009. Spatio-temporal dynamics and evolution of land use change and landscape pattern in response to rapid urbanization. Landscape and Urban Planning, 92(3/4): 187-198.

Dietz T, Ostrom E, Stern P C, 2003. The struggle to govern the commons. Science, 302(5652): 1907-1912.

Doerner K F, Gutjahr W J, Hartl R F et al., 2006. Pareto ant colony optimization with ILP preprocessing in multiobjective project portfolio selection. European Journal of Operational Research, 171(3): 830-841.

Dongfeng Y, Chengzhi Y, Ying L, 2013. Urbanization and sustainability in China: An analysis based on the urbanization Kuznets-curve. Planning Theory, 12(4): 391-405.

Ehrlich P R, Holdren J P, 1971. Impact of population growth. Science, 171(3977): 1212-1217. 
Erb K H, Haberl H, DeFries R et al., 2012. Pushing the planetary boundaries. Science, 338(6113): 1419.

Escudero M, Lozano A, Hierro J et al., 2014. Urban influence on increasing ozone concentrations in a characteristic Mediterranean agglomeration. Atmospheric Environment, 99: 322-332.

Fang C L, 2011. China's urban industrial allocation and decision support system. Beijing: Science Press. (in Chinese)

Fang C L, 2015. Important progress and future direction of studies on China's urban agglomerations. Journal of Geographical Sciences, 25(8): 1003-1024.

Fang C L, Bao C, Huang J C, 2007. Management implications to water resources constraint force on socio-economic system in rapid urbanization: A case study of the Hexi Corridor, NW China. Water Resources Management, 21(9): 1613-1633.

Fang C L, Lin X Q, 2009. The eco-environmental guarantee for China's urbanization process. Journal of Geographical Sciences, 19(1): 95-106.

Fang C L, Liu H M, Li G D et al., 2015. Estimating the impact of urbanization on air quality in China using spatial regression models. Sustainability, 7(11): 15570.

Fang C L, Wang Y, Fang J W, 2016. A comprehensive assessment of urban vulnerability and its spatial differentiation in China. Journal of Geographical Sciences, 26(2): 153-170.

Fang C L, Wang J, 2013. A theoretical analysis of interactive coercing effects between urbanization and eco-environment. Chinese Geographical Science, 23(2): 147-162.

Fang C L, Yang Y M, 2006. Basic laws of the interactive coupling system of urbanization and ecological environment. Arid Land Geography, 29(1): 1-8. (in Chinese)

Fang K, Heijungs R, de Snoo G R, 2014. Theoretical exploration for the combination of the ecological, energy, carbon, and water footprints: Overview of a footprint family. Ecological Indicators, 36: 508-518.

Fang K, Heijungs R, de Snoo G R, 2015. Understanding the complementary linkages between environmental footprints and planetary boundaries in a footprint-boundary environmental sustainability assessment framework. Ecological Economics, 114: 218-226.

Feitosa F F, Le Q B, Vlek P L G, 2011. Multi-agent simulator for urban segregation (MASUS): A tool to explore alternatives for promoting inclusive cities. Computers Environment and Urban Systems, 35(2): $104-115$.

Feng J, Wang J, Yan Z, 2014. Impact of anthropogenic heat release on regional climate in three vast urban agglomerations in China. Advances in Atmospheric Sciences, 31(2): 363-373.

Ferreira N, Poco J, Vo H T et al., 2013. Visual exploration of big spatio-temporal urban data: A study of New York city taxi trips. IEEE Transactions on Visualization and Computer Graphics, 19(12): 2149-2158.

Filatova T, Polhill J G, van Ewijk S, 2015. Regime shifts in coupled socio-environmental systems: Review of modelling challenges and approaches. Environmental Modelling \& Software, 151: 500-516.

Folke C, 2006. Resilience: The emergence of a perspective for social-ecological systems analyses. Global Environmental Change-Human and Policy Dimensions, 16(3): 253-267.

Folke C, Hahn T, Olsson P et al., 2005. Adaptive governance of social-ecological systems. Annual Review of Environment and Resources, 30: 441-473.

Friedl B, Getzner M, 2003. Determinants of $\mathrm{CO}_{2}$ emissions in a small open economy. Ecological Economics, 45(1): 133-148.

Galaz V, Biermann F, Crona B et al., 2012. 'Planetary boundaries': Exploring the challenges for global environmental governance. Current Opinion in Environmental Sustainability, 4(1): 80-87.

Galli A, Wiedmann T, Ercin E et al., 2012. Integrating ecological, carbon and water footprint into a "footprint family" of indicators: Definition and role in tracking human pressure on the planet. Ecological Indicators, 16: $100-112$.

Gangadharan L, Valenzuela M A, 2001. Interrelationships between income, health and the environment: Extending the Environmental Kuznets Curve hypothesis. Ecological Economics, 36(3): 513-531.

Gen M, Cheng R, 2000. Genetic Algorithms and Engineering Optimization. John Wiley \& Sons.

Gerten D, Rockstrom J, Heinke J et al., 2015. Response to Comment on "Planetary boundaries: Guiding human development on a changing planet". Science, 348(6240).

Gill S E, Handley J F, Ennos A R et al., 2008. Characterising the urban environment of UK cities and towns: A template for landscape planning. Landscape and Urban Planning, 87(3): 210-222.

Grimm N B, Faeth S H, Golubiewski N E et al., 2008a. Global change and the ecology of cities. Science, 319(5864): 756-760.

Grimm N B, Foster D, Groffman P et al., 2008b. The changing landscape: Ecosystem responses to urbanization and pollution across climatic and societal gradients. Frontiers in Ecology and the Environment, 6(5): 264-272.

Grimm N B, Grove J M, Pickett S T A et al., 2000. Integrated approaches to long-term studies of urban ecological systems. Bioscience, 50(7): 571-584.

Grossman G M, Krueger A B, 1994. Economic growth and the environment. Social Science Electronic 
Publishing, 110(2): 353-377.

Gu B, Dong X, Peng C et al., 2012. The long-term impact of urbanization on nitrogen patterns and dynamics in Shanghai, China. Environmental Pollution, 171: 30-37.

$\mathrm{Gu} \mathrm{C}, \mathrm{Hu} \mathrm{L}$, Zhang X et al., 2011. Climate change and urbanization in the Yangtze River Delta. Habitat International, 35(4): 544-552.

Gunderson L H, 2001. Panarchy: Understanding Transformations in Human and Natural Systems. Island Press.

Gustafson S, Heynen N, Rice J L et al., 2014. Megapolitan political ecology and urban metabolism in southern Appalachia. Professional Geographer, 66(4): 664-675.

Gwo-Hshiung T, 2010. Multiple attribute decision making: Methods and applications. Multiple Attribute Decision Making: Methods and Applications.

Haas J, Ban Y, 2014. Urban growth and environmental impacts in Jing-Jin-Ji, the Yangtze, River Delta and the Pearl River Delta. International Journal of Applied Earth Observation and Geoinformation, 30: $42-55$.

Haase D, 2009. Effects of urbanisation on the water balance: A long-term trajectory. Environmental Impact Assessment Review, 29(4): 211-219.

Habitat U, 1996. An urbanizing world, global report on human settlements. Nairobi: UN Human Settlements Programme.

Hamer A J, McDonnell M J, 2008. Amphibian ecology and conservation in the urbanising world: A review. Biological Conservation, 141(10): 2432-2449.

Han B L, Liu H X, Wang R S, 2015a. Urban ecological security assessment for cities in the Beijing-Tianjin-Hebei metropolitan region based on fuzzy and entropy methods. Ecological Modelling, 318: 217-225.

Han B L, Wang R S, Tao Y et al., 2014. Urban population agglomeration in view of complex ecological niche: A case study on Chinese prefecture cities. Ecological Indicators, 47: 128-136.

Han L, Zhou W, Li W et al., 2015b. Meteorological and urban landscape factors on severe air pollution in Beijing. Journal of the Air \& Waste Management Association, 65(7): 782-787.

Hansen A J, Knight R L, Marzluff J M et al., 2005. Effects of exurban development on biodiversity: Patterns, mechanisms, and research needs. Ecological Applications, 15(6): 1893-1905.

Hayashi T, Tokunaga T, Aichi M et al., 2009. Effects of human activities and urbanization on groundwater environments: An example from the aquifer system of Tokyo and the surrounding area. Science of the Total Environment, 407(9): 3165-3172.

He C, Zhang T, Rui W, 2012. Air quality in urban China. Eurasian Geography and Economics, 53(6): 750-771.

He J, 2009. China's industrial SO2 emissions and its economic determinants: EKC's reduced vs. structural model and the role of international trade. Environment and Development Economics, 14: 227-262.

Heckbert S, Baynes T, Reeson A, 2010. Agent-based modeling in ecological economics. In: Limburg K, Costanza R (eds.), Ecological Economics Reviews. Annals of the New York Academy of Sciences.

Heerink N, Mulatu A, Bulte E, 2001. Income inequality and the environment: Aggregation bias in environmental Kuznets curves. Ecological Economics, 38(3): 359-367.

Hellweg S, Doka G, Finnveden G et al., 2005. Assessing the eco-efficiency of end-of-pipe technologies with the environmental cost efficiency indicator. Journal of Industrial Ecology, 9(4): 189-203.

Henderson V, Storeygard A, Deichmann U, 2015. Has climate change driven urbanization in Africa? Working Paper, London School of Economics.

Hey A J, Tansley S, Tolle K M, 2009. The fourth paradigm: Data-intensive scientific discovery. Microsoft Research Redmond, WA.

Hoekstra A Y, Wiedmann T O, 2014. Humanity’s unsustainable environmental footprint. Science, 344(6188): 1114-1117.

Holling C S, 2001. Understanding the complexity of economic, ecological, and social systems. Ecosystems, 4(5): 390-405.

Huang J C, Fang C L, 2003. Analysis of coupling mechanism and rules between urbanization and eco-environment. Geographical Research, 22(2): 211-220. (in Chinese)

Hubacek K, Guan D B, Barrett J et al., 2009. Environmental implications of urbanization and lifestyle change in China: Ecological and Water Footprints. Journal of Cleaner Production, 17(14): 1241-1248.

Hull V, Tuanmu M-N, Liu J, 2015. Synthesis of human-nature feedbacks. Ecology and Society, 20(3): 17.

Imhoff M L, Bounoua L, DeFries R et al., 2004. The consequences of urban land transformation on net primary productivity in the United States. Remote Sensing of Environment, 89(4): 434-443.

Jain R K, Moura J M F, Kontokosta C E, 2014. Big data plus big cities: Graph signals of urban air pollution. Ieee Signal Processing Magazine, 31(5): 130-136.

Jalil A, Mahmud S F, 2009. Environment Kuznets curve for $\mathrm{CO}_{2}$ emissions: A cointegration analysis for China. Energy Policy, 37(12): 5167-5172.

Jaramillo F, Destouni G, 2015. Comment on "Planetary boundaries: Guiding human development on a changing 
planet". Science, 348(6240).

Jjumba A, Dragicevic S, 2012. High resolution urban land-use change modeling: Agent icity approach. Applied Spatial Analysis and Policy, 5(4): 291-315.

Jones P D, Groisman P Y, Coughlan M et al., 1990. Assessment of urbanization effects in time series of surface air temperature over land. Nature, 347(6289): 169-172.

Kalnay E, Cai M, 2003. Impact of urbanization and land-use change on climate. Nature, 423(6939): 528-531.

Kan H, Chen B, Hong C, 2009. Health impact of outdoor air pollution in China: Current knowledge and future research needs. Environ Health Perspect, 117(5): A187.

Kareiva P, 2012. Bankrupting nature: Denying our planetary boundaries. Nature, 490(7421): 474-475.

Kates R, Clark W, Corell R et al., 2001. Environment and development. Sustainability science. Science, 292(5517): 641.

Kennedy C, Pincetl S, Bunje P, 2011. The study of urban metabolism and its applications to urban planning and design. Environmental Pollution, 159(8/9): 1965-1973.

Kennedy C, Stewart I D, Ibrahim N et al., 2014. Developing a multi-layered indicator set for urban metabolism studies in megacities. Ecological Indicators, 47: 7-15.

Kindberg T, Chalmers M, Paulos E, 2007. Urban computing. IEEE Pervasive Computing, 6(3): 18-20.

Kline J D, Moses A, Alig R J, 2001. Integrating urbanization into landscape-level ecological assessments. Ecosystems, 4(1): 3-18.

Kohsaka R, 2010. Developing biodiversity indicators for cities: applying the DPSIR model to Nagoya and integrating social and ecological aspects. Ecological Research, 25(5): 925-936.

Kukka H, Foth M, Dey A K, 2015. Transdisciplinary approaches to urban computing. International Journal of Human-Computer Studies, 81: 1-3.

Kurihara S, Fukuda K, Hirotsu T et al., 2005. Multi-agent human-environment interaction framework for the ubiquitous environment. In: Ishida $\mathrm{T}$ et al. (eds.), Massively Multi-Agent Systems I. Lecture Notes in Artificial Intelligence.

Kurucu Y, Chiristina N K, 2008. Monitoring the impacts of urbanization and industrialization on the agricultural land and environment of the Torbali, Izmir region, Turkey. Environmental Monitoring and Assessment, 136(1-3): 289-297.

Lenschow A, Newig J, Challies E, 2015. Globalization's limits to the environmental state? Integrating telecoupling into global environmental governance. Environmental Politics, 25(1): 136-159.

Leslie H M, Basurto X, Nenadovic M et al., 2015. Operationalizing the social-ecological systems framework to assess sustainability. Proceedings of the National Academy of Sciences of the United States of America, 112(19): 5979-5984.

Lewis S L, 2012. We must set planetary boundaries wisely. Nature, 485(7399): 417.

Li X, Wang L, Ji D et al., 2013. Characterization of the size-segregated water-soluble inorganic ions in the Jing-Jin-Ji urban agglomeration: Spatial/temporal variability, size distribution and sources. Atmospheric Environment, 77: 250-259.

Li Y, Li Y, Zhou Y et al., 2012. Investigation of a coupling model of coordination between urbanization and the environment. Journal of Environmental Management, 98: 127-133.

Liddle B, 2013. Urban density and climate change: A STIRPAT analysis using city-level data. Journal of Transport Geography, 28: 22-29.

Liddle B, Lung S, 2010. Age-structure, urbanization, and climate change in developed countries: Revisiting STIRPAT for disaggregated population and consumption-related environmental impacts. Population and Environment, 31(5): 317-343.

Lin B Q, Ouyang X L, 2014. Energy demand in China: Comparison of characteristics between the US and China in rapid urbanization stage. Energy Conversion and Management, 79: 128-139.

Liu J, Diamond J, 2005. China's environment in a globalizing world. Nature, 435(7046): 1179-1186.

Liu J, Dietz T, Carpenter S R et al., 2007a. Complexity of coupled human and natural systems. Science, 317(5844): 1513-1516.

Liu J G, Dietz T, Carpenter S R et al., 2007b. Complexity of coupled human and natural systems. Science, 317(5844): 1513-1516.

Liu J G, Dietz T, Carpenter S R et al., 2007c. Coupled human and natural systems. Ambio, 36(8): 639-649.

Liu J G, Hull V, Batistella M et al., 2013. Framing sustainability in a telecoupled world. Ecology and Society, 18(2): 344-365.

Liu J G, Mooney H, Hull V et al., 2015. Sustainability. Systems integration for global sustainability. Science, 347(6225): 1258832.

Liu Y, Xu J, Luo H, 2014. An integrated approach to modelling the economy-society-ecology system in urbanization process. Sustainability, 6(4): 1946-1972.

Liu Y B, Li R D, Song X F, 2005. Grey associative analysis of regional urbanization and eco-environment 
coupling in China. Acta Geographica Sinica, 60(2): 237-247. (in Chinese)

Liu Y B, Yao C S, Wang G X et al., 2011. An integrated sustainable development approach to modeling the eco-environmental effects from urbanization. Ecological Indicators, 11(6): 1599-1608.

Liu Z, Guan D, Moore S et al., 2015. Climate policy: Steps to China's carbon peak. Nature, 522: $279-281$.

Lorenz K, Lal R, 2015. Managing soil carbon stocks to enhance the resilience of urban ecosystems. Carbon Management, 6(1/2): 35-50.

Luo H B, Huang G, Wu X M et al., 2009. Ecological engineering analysis and eco-hydrodynamic simulation of tidal rivers in Shenzhen City of China. Ecological Engineering, 35(8): 1129-1137.

Ma S J, Wang R S, 1984. Social-economic-natural complex ecosystem. Acta Ecologica Sinica, 4(1): 1-9. (in Chinese)

Mansencal N, Auvert B, N'Guetta R et al., 2013. Prospective assessment of incidence of Tako-Tsubo cardiomyopathy in a very large urban agglomeration. International Journal of Cardiology, 168(3): 2791-2795.

Manson S M, 2008. Does scale exist? An epistemological scale continuum for complex human-environment systems, Geoforum, 39(2): 776-788.

Martinez-Zarzoso I, Maruotti A, 2011. The impact of urbanization on $\mathrm{CO}_{2}$ emissions: Evidence from developing countries. Ecological Economics, 70(7): 1344-1353.

Matus K, Nam K-M, Selin N E et al., 2012. Health damages from air pollution in China. Global Environmental Change, 22(1): 55-66.

McDonald R I, Kareiva P, Formana R T T, 2008. The implications of current and future urbanization for global protected areas and biodiversity conservation. Biological Conservation, 141(6): 1695-1703.

McGinnis M D, Ostrom E, 2014. Social-ecological system framework: Initial changes and continuing challenges. Ecology and Society, 19(2): 30.

Meerow S, Newell J P, 2015. Resilience and complexity: A bibliometric review and prospects for industrial ecology. Journal of Industrial Ecology, 19(2): 236-251.

Ming Y, 2015. Energy development and urbanization in China. Energy \& Environment, 26(1/2): 1-14.

Montgomery M R, 2008. The urban transformation of the developing world. Science, 319(5864): 761-764.

Moore S A, 2007. In the nature of cities: Urban political ecology and the politics of urban metabolism. Urban Geography, 28(2): 206-208.

Moser S C, Hart J A F, 2015. The long arm of climate change: Societal teleconnections and the future of climate change impacts studies. Climatic Change, 129(1/2): 13-26.

Murata T, Ishibuchi H, Tanaka H, 1996. Multi-objective genetic algorithm and its applications to flowshop scheduling. Computers \& Industrial Engineering, 30(4): 957-968.

Newell B, Crumley C L, Hassan N et al., 2005. A conceptual template for integrative human-environment research. Global Environmental Change, 15(4): 299-307.

Newell J P, Cousins J J, 2015. The boundaries of urban metabolism: Towards a political-industrial ecology. Progress in Human Geography, 39(6): 702-728.

Noorpoor A R, Kudahi S N, 2015. $\mathrm{CO}_{2}$ emissions from Iran's power sector and analysis of the influencing factors using the stochastic impacts by regression on population, affluence and technology (STIRPAT) model. Carbon Management, 6(3/4): 101-116.

Norberg J, Cumming G S, 2013. Complexity Theory for a Sustainable Future. Columbia University Press.

Normile D, 2008. China's living laboratory in urbanization. Science 319(5864): 740-743.

Orubu C O, Omotor D G, 2011. Environmental quality and economic growth: Searching for environmental Kuznets curves for air and water pollutants in Africa. Energy Policy, 39(7): 4178-4188.

Pachauri R K, Allen M, Barros V et al., 2014. Climate Change 2014: Synthesis Report. Contribution of Working Groups I, II and III to the Fifth Assessment Report of the Intergovernmental Panel on Climate Change.

Parrish D D, Zhu T, 2009. Clean air for megacities. Science, 326(5953): 674-675.

Pelling M, 2010. Adaptation to Climate Change: From Resilience to Transformation. Routledge.

Pereira H M, Leadley P W, Proença V et al., 2010. Scenarios for global biodiversity in the 21 st century. Science, 330(6010): 1496-1501.

Pfeffer K, Verrest H, Poorthuis A, 2015. Big data for better urban life?: An exploratory study of critical urban issues in two caribbean cities: Paramaribo (Suriname) and Port of Spain (Trinidad and Tobago). European Journal of Development Research, 27(4): 505-522.

Pickett S, Cadenasso M, Grove J, 2005. Biocomplexity in coupled natural-human systems: A multidimensional framework. Ecosystems, 8(3): 225-232.

Pickett S T, Buckley G L, Kaushal S S et al., 2011. Social-ecological science in the humane metropolis. Urban ecosystems, 14(3): 319-339.

Pijanowski B C, Tayyebi A, Doucette J et al., 2014. A big data urban growth simulation at a national scale: Configuring the GIS and neural network based Land Transformation Model to run in a High Performance 
Computing (HPC) environment. Environmental Modelling \& Software, 51: 250-268.

Polhill J G, Filatova T, Schlüter M et al., 2016. Modelling systemic change in coupled socio-environmental systems. Environmental Modelling \& Software, 75: 318-332.

Popa P, Timofti M, Voiculescu M et al., 2012. Study of physico-chemical characteristics of wastewater in an urban agglomeration in Romania. Scientific World Journal, 2012: 549028.

Poruschi L, 2015. Sustainable Urban Metabolism. Urban Policy and Research, 33(1): 123-125.

Poumanyvong P, Kaneko S, 2010. Does urbanization lead to less energy use and lower $\mathrm{CO}_{2}$ emissions? A cross-country analysis. Ecological Economics, 70(2): 434-444.

Power D J, Sharda R, 2007. Model-driven decision support systems: Concepts and research directions. Decision Support Systems, 43(3): 1044-1061.

Qi J G, Chen J Q, Wan S Q et al., 2012. Understanding the coupled natural and human systems in Dryland East Asia. Environmental Research Letters, 7(1): 15202-15207.

Qiao B, Fang C L, 2005a. The dynamic coupling model and its application of urbanization and eco-environment in Hexi Corridor. Journal of Geographical Sciences, 15(4): 491-499.

Qiao B, Fang C L, 2005b. The dynamic coupling model of the harmonious development between urbanization and eco-environment and its application in arid area. Acta Ecologica Sinica, 25(11): 3003-3009.

Qu L, Zhang T, Liang S, 2013. Waste management of urban agglomeration on a life cycle basis. Resources, Conservation and Recycling, 78: 47-53.

Ragnarsdottir K V, Sverdrup H U, Koca D, 2011. Challenging the planetary boundaries I: Basic principles of an integrated model for phosphorous supply dynamics and global population size. Applied Geochemistry, 26: S303-S306.

Ramaswami A, Weible C, Main D et al., 2012. A social-ecological-infrastructural systems framework for interdisciplinary study of sustainable city systems: An integrative curriculum across seven major disciplines. Journal of Industrial Ecology, 16(6): 801-813.

Rees W, Wackernagel M, 1996. Urban ecological footprints: Why cities cannot be sustainable - And why they are a key to sustainability. Environmental Impact Assessment Review, 16(4-6): 223-248.

Reid W V, Chen D, Goldfarb L et al., 2010. Earth system science for global sustainability: Grand challenges. Science, 330(6006): 916-917.

Ren W W, Zhong Y, Meligrana J et al., 2003. Urbanization, land use, and water quality in Shanghai 1947-1996. Environment International, 29(5): 649-659.

Ridoutt B G, Pfister S, 2014. There is still room for a footprint family without a life cycle approach: Comment on "Towards an integrated family of footprint indicators" response. Journal of Industrial Ecology, 18(1): 72.

Roberts T D, 2011. Applying the STIRPAT model in a post-Fordist landscape: Can a traditional econometric model work at the local level? Applied Geography, 31(2): 731-739.

Rockström J, Steffen W, Noone K et al., 2009. A safe operating space for humanity. Nature, 461(7263): $472-475$.

Rohde R A, Muller R A, 2015. Air pollution in China: Mapping of concentrations and sources. PloS One, 10(8): e0135749.

Salim R A, Shafiei S, 2014. Urbanization and renewable and non-renewable energy consumption in OECD countries: An empirical analysis. Economic Modelling, 38: 581-591.

Satterthwaite D, 2008. Cities' contribution to global warming: Notes on the allocation of greenhouse gas emissions. Environment and Urbanization, 20(2): 539-549.

Savard J-P L, Clergeau P, Mennechez G, 2000. Biodiversity concepts and urban ecosystems. Landscape and Urban Planning, 48(3): 131-142.

Schlueter M, McAllister R, Arlinghaus R et al., 2012. New horizons for managing the environment: A review of coupled social - ecological systems modeling. Natural Resource Modeling, 25(1): 219-272.

Scholz R W, Binder C R, 2011. Environmental literacy in science and society: From knowledge to decisions. Cambridge University Press.

Seto K C, Sanchez-Rodriguez R, Fragkias M, 2010. The New Geography of Contemporary Urbanization and the Environment. In: Gadgil A, Liverman D M (eds.). Annual Review of Environment and Resources, Vol 35. Annual Review of Environment and Resources. Palo Alto: Annual Reviews.

Shahbaz M, Sbia R, Hamdi H et al., 2014. Economic growth, electricity consumption, urbanization and environmental degradation relationship in United Arab Emirates. Ecological Indicators, 45: 622-631.

Shahrokni H, Arman L, Lazarevic D et al., 2015. Implementing smart urban metabolism in the stockholm royal seaport: Smart city SRS. Journal of Industrial Ecology, 19(5): 917-929.

Shao M, Tang X, Zhang Y et al., 2006. City clusters in China: Air and surface water pollution. Frontiers in Ecology and the Environment, 4(7): 353-361.

Shearmur R, 2015. Dazzled by data: Big Data, the census and urban geography. Urban Geography, 36(7): 965-968.

Shklovski I, Chang M F, 2006. Urban computing: Navigating space and context. Computer, 39(9): 36-37. 
Singh S J, Haberl H, Chertow M et al., 2012. Long term socio-ecological research: Studies in society-nature interactions across spatial and temporal scales. Springer Science \& Business Media.

Srinivasan V, Seto K C, Emerson R et al., 2013. The impact of urbanization on water vulnerability: A coupled human-environment system approach for Chennai, India. Global Environmental Change-Human and Policy Dimensions, 23(1): 229-239.

Steen-Adams M M, Langston N, Adams M D O et al., 2015. Historical framework to explain long-term coupled human and natural system feedbacks: Application to a multiple-ownership forest landscape in the northern Great Lakes region, USA. Ecology and Society, 20(1): 28.

Steffen W, Richardson K, Rockstrom J et al., 2015. Sustainability. Planetary boundaries: Guiding human development on a changing planet. Science, 347(6223): 1259855.

Stevenson R J, 2011. A revised framework for coupled human and natural systems, propagating thresholds, and managing environmental problems. Physics and Chemistry of the Earth, 36(9-11): 342-351.

Suh N P, 2005. Complexity: Theory and Applications. Oxford University Press on Demand.

Summers D M, Bryan B A, Meyer W S et al., 2015. Simple models for managing complex social-ecological systems: The Landscape Futures Analysis Tool (LFAT). Environmental Modelling \& Software, 63: 217-229.

Swyngedouw E, 2009. The antinomies of the postpolitical city: In search of a democratic politics of environmental production. International Journal of Urban and Regional Research, 33(3): 601-620.

Tan C J, Hanoun S, Lim C P, 2015. A multi-objective evolutionary algorithm-based decision support system: A case study on job-shop scheduling in manufacturing, Systems Conference (SysCon), 2015 9th Annual IEEE International. IEEE, pp. 170-174.

Tang Z, 2015. An integrated approach to evaluating the coupling coordination between tourism and the environment. Tourism Management, 46: 11-19.

Tian G, Ouyang Y, Quan Q et al., 2011. Simulating spatiotemporal dynamics of urbanization with multi-agent systems: A case study of the Phoenix metropolitan region, USA. Ecological Modelling, 222(5): 1129-1138.

Torrens P M, Benenson I, 2005. Geographic automata systems. International Journal of Geographical Information Science, 19(4): 385-412.

Townsend A M, 2000. Life in the real-time city: Mobile telephones and urban metabolism. Journal of Urban Technology, 7(2): 85-104.

Trosper R L, 2005. Emergence unites ecology and society. Ecology and Society, 10(1): 14.

Trusilova K, Churkina G, 2008. The response of the terrestrial biosphere to urbanization: Land cover conversion, climate, and urban pollution. Biogeosciences, 5(6): 1505-1515.

Ulungu E, Teghem J, Fortemps P et al., 1999. MOSA method: A tool for solving multiobjective combinatorial optimization problems. Journal of Multicriteria Decision Analysis, 8(4): 221.

Van Delden H, Hurkens J, 2011. A generic Integrated Spatial Decision Support System for urban and regional planning, Keynote presented at MODSIM11 International Congress on Modelling and Simulation, Perth, Australia.

Venkatesan A K, Ahmad S, Johnson W et al., 2011. Systems dynamic model to forecast salinity load to the Colorado River due to urbanization within the Las Vegas Valley. Science of the Total Environment, 409(13): 2616-2625.

Wackernagel M, Rees W, 1998. Our Ecological Footprint: Reducing Human Impact on the Earth. New Society Publishers.

Waggoner P E, Ausubel J H, 2002. A framework for sustainability science: A renovated IPAT identity. Proceedings of the National Academy of Sciences, 99(12): 7860-7865.

Walker B, Carpenter S, Anderies J et al., 2002. Resilience management in social-ecological systems: A working hypothesis for a participatory approach. Conservation Ecology, 6(1): 840-842.

Walker B, Hollin C S, Carpenter S R et al., 2004. Resilience, adaptability and transformability in social-ecological systems. Ecology and Society, 9(2): 3438-3447.

Walker B, Meyers J A, 2004. Thresholds in ecological and social ecological systems: A developing database. Ecology and Society, 9(2): 3.

Walker B, Salt D, 2012. Resilience Thinking: Sustaining Ecosystems and People in a Changing World. Island Press.

Wang H, Horton R, 2015. Tackling climate change: The greatest opportunity for global health. The Lancet, 386(10006): 1798-1799.

Wang P, Wu W S, Zhu B Z et al., 2013. Examining the impact factors of energy-related $\mathrm{CO}_{2}$ emissions using the STIRPAT model in Guangdong Province, China. Applied Energy, 106: 65-71.

Wang R, Li F, Hu D et al., 2011. Understanding eco-complexity: Social-economic-natural complex ecosystem approach. Ecological Complexity, 8(1): 15-29.

Wang S, Fang C, Guan X et al., 2014a. Urbanisation, energy consumption, and carbon dioxide emissions in China: A panel data analysis of China's provinces. Applied Energy, 136: 738-749. 
Wang S, Ma H, Zhao Y, 2014b. Exploring the relationship between urbanization and the eco-environment: A case study of Beijing-Tianjin-Hebei region. Ecological Indicators, 45: 171-183.

Wei Y D, Ye X Y, 2014. Urbanization, urban land expansion and environmental change in China. Stochastic Environmental Research and Risk Assessment, 28(4): 757-765.

Wei Y L, Bao L J, Wu C C et al., 2014. Association of soil polycyclic aromatic hydrocarbon levels and anthropogenic impacts in a rapidly urbanizing region: Spatial distribution, soil-air exchange and ecological risk. Science of the Total Environment, 473: 676-684.

Werner B, McNamara D, 2007. Dynamics of coupled human-landscape systems. Geomorphology, 91(3): 393-407.

Wierzbicki A, Makowski M, Wessels J, 2000. Model-based decision support methodology with environmental applications. Kluwer Academic Dordrecht, The Netherlands.

Wolch J R, Byrne J, Newell J P, 2014. Urban green space, public health, and environmental justice: The challenge of making cities 'just green enough'. Landscape and Urban Planning, 125: 234-244.

Wolman A, 1965. The metabolism of cities. Scientific American, 213(3): 179-190.

Xia X H, Hu Y, Alsaedi A et al., 2015. Structure decomposition analysis for energy-related GHG emission in Beijing: Urban metabolism and hierarchical structure. Ecological Informatics, 26: 60-69.

Xin J, Wang Y, Wang L et al., 2012. Reductions of PM2.5 in Beijing-Tianjin-Hebei urban agglomerations during the 2008 Olympic Games. Advances in Atmospheric Sciences, 29(6): 1330-1342.

Yang L, Ouyang H, Fang K et al., 2015. Evaluation of regional environmental efficiencies in China based on super-efficiency-DEA. Ecological Indicators, 51: 13-19.

Yeh W C, Chuang M C, 2011. Using multi-objective genetic algorithm for partner selection in green supply chain problems. Expert Systems with Applications, 38(4): 4244-4253.

York R, Rosa E A, Dietz T, 2003a. A rift in modernity? Assessing the anthropogenic sources of global climate change with the STIRPAT model. International Journal of Sociology and Social Policy, 23(10): 31-51.

York R, Rosa E A, Dietz T, 2003b. STIRPAT, IPAT and ImPACT: Analytic tools for unpacking the driving forces of environmental impacts. Ecological Economics, 46(3): 351-365.

Yu P L, 2013. Multiple-criteria decision making: Concepts, techniques, and extensions. Springer Science \& Business Media.

Yuan R, Zhao T, Xu X S et al., 2015. Regional characteristics of impact factors for energy-related $\mathrm{CO}_{2}$ emissions in China, 1997-2010: Evidence from tests for threshold effects based on the STIRPAT model. Environmental Modeling \& Assessment, 20(2): 129-144.

Zanella A, Camanho A S, Dias T G, 2014. The assessment of cities' livability integrating human wellbeing and environmental impact. Annals of Operations Research, 226(1): 695-726.

Zawar-Reza P, Appelhans T, Gharaylou M et al., 2010. Mesoscale controls on particulate matter pollution for a mega city in a semi-arid mountainous environment: Tehran, Iran. International Journal of Environment and Pollution, 41(1/2): 166-183.

Zhang Q, He K, Huo H, 2012. Policy: Cleaning China's air. Nature, 484(7393): 161-162.

Zhang S M, Zhang B L, Zhang L et al., 2010. Spatiotemporal evolution of urban land uses in modern urbanization of China. Chinese Geographical Science, 20(2): 132-138.

Zhang Y, Yang Z F, Fath B D et al., 2010. Ecological network analysis of an urban energy metabolic system: Model development, and a case study of four Chinese cities. Ecological Modelling, 221(16): 1865-1879.

Zhang Y, Yang Z F, Liu G Y et al., 2011. Emergy analysis of the urban metabolism of Beijing. Ecological Modelling, 222(14): 2377-2384.

Zhang Y, Yang Z F, Yu X Y, 2015a. Urban metabolism: A review of current knowledge and directions for future study. Environmental Science \& Technology, 49(19): 11247-11263.

Zhang Z, Zhang X, Gong D et al., 2015b. Evolution of surface $\mathrm{O}_{3}$ and PM2.5 concentrations and their relationships with meteorological conditions over the last decade in Beijing. Atmospheric Environment, 108: 67-75.

Zhao J, Chen S, Wang $\mathrm{H}$ et al., 2012. Quantifying the impacts of socio-economic factors on air quality in Chinese cities from 2000 to 2009. Environmental Pollution, 167: 148-154.

Zheng Y, 2015. Methodologies for cross-domain data fusion: An overview. IEEE Transactions on Big Data, 1(1): 16-34.

Zheng Y, Capra L, Wolfson O et al., 2014. Urban computing: Concepts, methodologies, and applications. Acm Transactions on Intelligent Systems and Technology, 5(3): 222-235.

Zhu H M, You W H, Zeng Z F, 2012. Urbanization and $\mathrm{CO}_{2}$ emissions: A semi-parametric panel data analysis. Economics Letters, 117(3): 848-850. 